\title{
Are the poor worse at dealing with ambiguity?
}

\section{Chen $\mathbf{L i}^{1}$}

\begin{abstract}
This paper studies the relationship between people's ambiguity attitudes and income in the field using language as a natural source of ambiguity. It shows that the method of Baillon et al. (2017b) can be adapted for field studies, providing ambiguity measurement tasks that are more comprehensible for nonacademic subjects. Ambiguity attitudes were elicited in two groups of Chinese adolescents (poor rural and rich urban), among whom the income variation is big. In the rural group the poorer are both more ambiguity averse and more a-insensitive, whereas in the urban group the richer are more a-insensitivite. On average, the poor rural adolescents are worse at dealing with ambiguity than their urban counterparts. A-insensitivity, which measures people's understanding of an ambiguous situation, is an important but sometimes neglected component of ambiguity attitude. Policies aiming to help people improve decisions may focus more on reducing a-insensitivity as this cognitive bias is more likely to be influenced by intervention than people's intrinsic aversion towards ambiguity.
\end{abstract}

Keywords Linguistic ambiguity · Ambiguity aversion · Income dependence · A-insensitivity

JEL Classifications D81 - C93 - O12

Electronic supplementary material The online version of this article (https://doi.org/10.1007/s11166-017-9262-2) contains supplementary material, which is available to authorized users.

Chen Li

c.li@ese.eur.nl

1 Erasmus School of Economics, Erasmus University Rotterdam, Tinbergen Building H12-29, Burgemeester Oudlaan 50, Rotterdam, Netherlands 


\section{Introduction}

For the poor whose lives are highly exposed to uncertainties, the way they deal with these uncertainties can affect their well-being substantially. Literature on the relationship between risk aversion and the poverty trap (Yesuf and Bluffstone 2009; Spears 2013) suggests that the poor being more risk averse may further trap them in poverty, as they will be less willing to invest in new technologies. "Thus they will remain poor, with processes of capital investment and innovation being confined to those people who are economically secure and in possession of sufficient defence against risk to be willing to invest and innovate" (Weeks 1970).

In reality, uncertainty goes beyond risk, and people's attitudes towards uncertainty cannot be captured by risk aversion alone. In everyday life, we mostly face situations with no well-defined probabilities - ambiguity. Research on decision under ambiguity has shown that people are ambiguity averse, preferring risky bets to ambiguous ones (Ellsberg 1961; Halevy 2007; Trautmann and van de Kuilen 2015). And ambiguity aversion has predictive power for real life decisions (Ross et al. 2012; Engle-Warnick et al. 2011; Sutter et al. 2013; Bianchi and Tallon 2014; Dimmock et al. 2016a, b). However, the literature on the relationship between risk aversion and income ${ }^{1}$ is much richer than the literature on the relationship between ambiguity aversion and income (Akay et al. 2012; Butler et al. 2014; Dimmock et al. 2016b). The main reason for this gap in the literature is that until recently no tools were available to measure ambiguity attitudes in natural circumstances.

This paper is the first to study the relationship between people's ambiguity attitudes and income in the field using a natural source of ambiguity - language. One challenge for field studies with non-academic subjects is that the commonly used experimental tasks are difficult for these subjects to understand. Low comprehension levels introduce noise and therefore reduce both the internal and external validity of experimental measures. The comprehension problem is especially severe for ambiguity measurements as they often involve abstract and artificial decision problems. A methodological contribution of this paper to ambiguity theory is that it shows how the new measurement method of Baillon et al. (2017b) can be adapted and applied in field studies. Baillon et al. (2017b) were the first to measure ambiguity attitudes for natural events, but they did so in the lab with sophisticated academic subjects. This paper adapts their measurement to a decision context involving uncertainties concerning unknown meanings of foreign phrases. This is a familiar decision context for the subjects in this study, Chinese high school adolescents, who encounter similar exercises in foreign language courses. We show that our ambiguity attitude measurements have validity in the field and can provide insights into policy applications.

Besides the benefit of enhancing subjects' comprehension of experimental tasks, studying people's attitudes towards natural ambiguity is desirable in itself as emphasized by Ellsberg $(1961,2011)$. Studies exploring the richness of natural ambiguity sources have shown that people's attitudes vary across different sources (Heath and

\footnotetext{
${ }^{1}$ See for instance Kachelmeier and Shehata (1992), Ogaki and Zhang (2001), Cohen and Einav (2007), Brunnermeier and Nagel (2008), Yesuf and Bluffstone (2009), and the review in Meyer and Meyer (2005).
} 
Tversky 1991; Abdellaoui et al. 2011). Several sources of uncertainty, such as temperature and stock market returns, have been studied (Heath and Tversky 1991; Abdellaoui et al. 2011; Chew et al. 2012; Baillon et al. 2017b). This paper studies ambiguity generated by language. Signals in social interactions are often sent using ambiguous language. Important decisions, such as whether to enter a business contract or whether to pursue a romantic relationship, are made without all linguistic ambiguities resolved (Grant et al. 2014, 2016). In natural language, linguistic ambiguity refers to linguistic vagueness that is open to different interpretations. In decision theory, ambiguity refers to unknown probabilities. Linguistic ambiguity can be treated as a special case of decision-theoretic ambiguity, as demonstrated by Grant et al. (2014, 2016), Shattuck and Wagner (2016), and our experiment.

The big income variation of the current sample allows for better detection of the relationship between people's ambiguity attitudes and income. Two groups of Chinese adolescents (rural and urban) are recruited. The rural subjects are mostly from farming households in a small county who all receive financial aid from a nongovernmental organization. ${ }^{2}$ The urban subjects are high school students mostly from middle class households in a big city. The richest households are 70 (80) times richer than the poorest in the rural (urban) group. Also, the rural adolescents are on average 10 times poorer than their urban counterparts. These big income variations make it possible to study the impact of income on ambiguity attitudes both within and between these two groups.

Within the rural group, ambiguity aversion decreases as income increases, whereas no effect is found for the urban adolescents. Previous studies in the developing world found no relationship between wealth and ambiguity aversion (Engle-Warnick et al. 2011; Akay et al. 2012; Cardenas and Carpenter 2013). These studies included proxies for wealth as control variables where the main research questions concerned the relationship between people's ambiguity attitudes and some real life decisions such as adoption of new technologies. Due to the different objectives of those studies, the wealth variations in their sample may not have been large enough to detect the impact of wealth on ambiguity aversion. The current study is the first to find a significant effect of income on ambiguity aversion. It shows that the poorest were also the most averse to ambiguity, which may further trap them in poverty. The lack of a significant impact of income on ambiguity aversion among the urban adolescents, whose household income is closer to people in the developed world, is consistent with the findings in a representative sample of the Dutch population by Dimmock et al. (2016b).

Regarding between-group comparisons, urban adolescents are less ambiguity averse than their rural counterparts. Some preceding studies made between-group comparisons. For instance, Akay et al. (2012) compared ambiguity aversion between Ethiopian farmers and Dutch university students and found no difference. The between-group comparison in his paper shares the problem with other preceding studies that causes of the findings are difficult to identify due to unobserved confounds. While I acknowledge that the current study could not exclude all confounds,

\footnotetext{
${ }^{2}$ This organization is called "One-School”, website: http://one-school.org.
} 
it has fewer than preceding studies. Both groups in this study come from China. Except for substantial differences in their household income, these two groups share many demographic traits such as age, education level, and cultural background. Although several factors may have contributed to the observed difference, the difference in their household income is very likely one of them. This is supported by the following observation. When looking at the subsample which consists only of adolescents whose household income is between the minimum of the urban group and the maximum of the rural group (i.e., where the rural and urban groups' income overlap), the rural-urban difference in ambiguity aversion is smaller than that in the rest of the sample.

Besides ambiguity aversion, this paper also investigates another important component of ambiguity attitude - a-insensitivity (Tversky and Fox 1995). Prevailing empirical findings show that people are usually a-insensitive, not being able to sufficiently discriminate between different levels of likelihood (Wakker 2010; Trautmann and van de Kuilen 2015). Ambiguity aversion reflects how much people dislike ambiguity from a motivational perspective, whereas a-insensitivity captures to what extent people understand the ambiguous decision situation from a cognitive perspective. Many studies, both empirical and theoretical, have shown that a-insensitivity is crucial in explaining the prevalent empirical patterns (Tversky and Wakker 1995; Gonzalez and Wu 1999; Viscusi and Chesson 1999; Kilka and Weber 2001; Viscusi and Evans 2006; Abdellaoui et al. 2011; Trautmann and van de Kuilen 2015; Dimmock et al. 2016b).

This paper is the first to measure a-insensitivity in the developing world. Both rural and urban adolescents were a-insensitive but rural adolescents were more so. Among the rural adolescents, the poorer were even more a-insensitive, whereas the opposite effect was found among the urban adolescents. Although some authors have argued for a normative basis to ambiguity aversion (Gilboa and Schmeidler 1989), such arguments are hard to conceive for a-insensitivity and have never been advanced. A-insensitivity is often regarded as a cognitive bias due to insufficient understanding of the uncertainties, and is therefore considered to be irrational. People who are a-insensitive are more susceptible to suboptimal decisions, such as not being able to sufficiently incorporate new information into decision making, overinvesting in low likelihood ambiguous opportunities, or overinvesting in removing ambiguity but not taking enough preventive measures to reduce ambiguity where it cannot be completely removed. In this sense, a more a-insensitive decision maker is equipped with less ability to cope with ambiguity.

The clear classification of a-insensitivity as irrational and its negative economic consequences make it especially interesting to study a-insensitivity among the poor in the developing world. Our findings on a-insensitivity suggest that both extremes, the poorest and the richest, are worse at dealing with ambiguity. However, the poor with extra financial constraints will suffer more from the negative consequences than the rich. On the positive side, the cognitive nature of a-insensitivity makes it easier to be reduced with proper decision aids — it is easier for people to learn about their cognitive mistakes than the emotional ones. Therefore policy makers aiming to improve people's decisions under uncertainty may want to focus more on reducing a-insensitivity. 


\section{Measurement of ambiguity attitudes}

This paper applies the elicitation method introduced by Baillon et al. (2017b) which provides quantitative measures of people's deviations from ambiguity neutrality. The advantage of having quantitative measures is that it helps us better understand what contributes most to these deviations (Viscusi 1995). We will consider the natural source of ambiguity generated by language, where the term source refers to events generated by the same mechanism of uncertainty (Tversky and Fox 1995; Chew and Sagi 2008; Abdellaoui et al. 2011). For example, in the Ellsberg two-color experiment, events concerning the known urn constitute one source of uncertainty (risk), whereas events concerning the unknown urn constitute another one. In this study, events concerning the true meaning of phrases in foreign languages constitute natural sources of uncertainty. Here is an example of an ambiguous source generated by a Dutch phrase:

\section{Let op.}

One of the following three phrases represents its true meaning: ${ }^{3}$

\section{(1) pay attention (2) upward (3) give up.}

A decision maker with no knowledge of Dutch, who therefore sees no reason to believe one alternative to be more likely than another, may find this ambiguity similar to the ambiguity generated by the unknown color composition in the Ellsberg paradox. When measuring ambiguity attitudes using artificial events, the symmetry assumption (all events are symmetric and are hence equally likely) is often used to control for beliefs (Dimmock et al. 2015, 2016b). But this symmetry does not hold in general for natural ambiguity sources. For instance, in our example, a decision maker who sees connections between Dutch and languages that he knows (for instance English) may have reasons to believe one phrase to be more likely than another. The potential asymmetry in beliefs makes it more difficult to control for decision makers' beliefs when eliciting their ambiguity attitudes. This difficulty is overcome by Baillon et al. (2017b)'s method.

This study considers six sources of ambiguity generated by phrases in the Shanghai dialect of Chinese, the Beijing dialect of Chinese, Japanese, Korean, English, and Dutch, respectively. The uncertainty about the true meaning of every phrase generates one source of uncertainty. Probabilistic sophistication (Machina and Schmeidler 1992) is assumed within each source (Chew and Sagi 2008; Abdellaoui et al. 2011). For every source, let $E_{i}(i=1,2,3)$ denote the event that the $i^{t h}$ alternative meaning is the true meaning of the Dutch phrase in Chinese. For instance, in the preceding example, $E_{1}$ denotes the event: the true meaning of "let op" is "pay attention". By definition, the $E_{i}$ 's are mutually exclusive and exhaustive, as one and only one of the three different alternatives is the true meaning. The union of two events: $E_{i} \cup E_{j}(i \neq j)$ is denoted $E_{i j}, i \neq j$. Events $E_{i}$ are referred to as single events and their unions $E_{i j}$ as composite events. In the experiment, subjects were asked to report their matching probabilities defined next.

\footnotetext{
${ }^{3}$ Original instructions were presented to subjects in Chinese.
} 
For every event $E\left(E_{i}\right.$ or $\left.E_{i j}\right)$ and fixed outcome ${ }^{4} X>0$, let $X_{E} 0$ denote an ambiguous lottery that pays $X$ if $E$ happens and 0 otherwise. Similarly, let $X_{q} 0$ denote a risky lottery that pays $X$ with probability $q$ and 0 with probability $1-q$.

Definition 1 The matching probability $m\left(m_{i}\right.$ or $\left.m_{i j}\right)$ of an event $E\left(E_{i}\right.$ or $\left.E_{i j}\right)$ is the probability such that the decision maker is indifferent between prospects $X_{E} 0$ and $X_{m} 0$.

In the experiment, the matching probability of an event is elicited using a choice list (see Section 3.3 for details). A decision maker's matching probability $m$ of an event $E$ reflects his subjective evaluation of the likelihood of event $E$, but distorted by his ambiguity attitude. Using matching probabilities, it is possible to measure ambiguity attitudes without the need to control for risk attitude (Dimmock et al. 2016b, Theorem 3.1). Let $p$ ( $p_{i}$ or $p_{i j}$ ) denote the decision maker's subjective probability of $E\left(E_{i}\right.$ or $\left.E_{i j}\right)$, which is assumed to be an additive probability measure within every source (justified by Chew and Sagi 2008 and Abdellaoui et al. 2011, who reconciled it with the Ellsberg paradox). For an ambiguity neutral decision maker, $m=p$ for all events. For an ambiguity-averse decision maker, his dislike of the ambiguity concerning his subjective probability $p$ makes him willing to sacrifice a positive amount of winning probability to get rid of this ambiguity. As a result, $m<p$. The difference between his matching probability $m$ and his subjective probability $p$ can be interpreted as an ambiguity premium. This concept of ambiguity premium is analogous to that of risk premium, where risk-averse decision makers are willing to pay the risk premium (in money) to avoid risk. Similarly, ambiguity averse decision makers are willing to pay an ambiguity premium (in winning probability) to avoid ambiguity.

To derive a decision maker's ambiguity attitude from the elicited matching probabilities, we need to control for his subjective probabilities. To this end, six matching probabilities were elicited for all single $\left(E_{1}, E_{2}\right.$, and $\left.E_{3}\right)$ and composite $\left(E_{12}, E_{23}\right.$, and $\left.E_{13}\right)$ events for every source of uncertainty. For an ambiguity neutral decision maker, we know that $m_{1}+m_{2}+m_{3}=1$ and $m_{12}+m_{23}+m_{31}=2$ without the need to know his subjective probabilities. Deviations from these ambiguity neutral benchmarks then give information about the decision makers' ambiguity attitudes. For instance, if a decision maker is ambiguity averse then $m_{1}+m_{2}+m_{3}<1$ and $m_{12}+m_{23}+m_{31}<2$.

Let $\overline{m_{s}}=\left(m_{1}+m_{2}+m_{3}\right) / 3$ denote the average matching probability of single events, and let $\overline{m_{c}}=\left(m_{12}+m_{13}+m_{23}\right) / 3$ denote the average matching probability of composite events. Under ambiguity neutrality, $\overline{m_{s}}+\overline{m_{c}}=1$.

Definition 2 The ambiguity aversion index is:

$$
b=1-\left(\overline{m_{s}}+\overline{m_{c}}\right) .
$$

\footnotetext{
${ }^{4}$ In the experiment, $X=40 \mathrm{RMB}$. At the time of the experiment, this was about $6.5 \mathrm{USD}$ and 5 EUR.
} 
The ambiguity aversion index captures how much a decision maker dislikes an ambiguous source on average relative to risk. The index measures the average deviation from ambiguity neutrality in the decision maker's matching probabilities of single and composite events. Under ambiguity aversion, the index is positive $(b>0)$, implying that the decision maker is willing to pay a positive ambiguity premium to avoid ambiguity. Similarly, ambiguity seeking implies a negative index $(b<0)$, and ambiguity neutrality implies $b=0$. The ambiguity aversion index coincides with a number of measures of ambiguity aversion proposed in the literature (Schmeidler 1989; Dow and da Costa Werlang 1992), where in the specific models considered by theses authors, expected utility is assumed for risk. The current measure of ambiguity aversion extends these measures to the general case.

Knowing how ambiguity averse/seeking decision makers are on average does not give us the full picture of their ambiguity attitudes. Empirical findings suggest that people are often ambiguity seeking for low likelihood events and ambiguity averse for high likelihood events (Kahn and Sarin 1988; Viscusi 1989; Hogarth and Einhorn 1990; Tversky and Fox 1995; Wakker 2010; Baillon et al. 2012; Trautmann and van de Kuilen 2015; Dimmock et al. 2016b). This likelihood-dependence of ambiguity aversion was predicted by Ellsberg $(1961,2011)$. However, it cannot be captured by the ambiguity aversion index. Hence, a second index of ambiguity attitude that can capture likelihood-dependence is defined: ambiguity-generated likelihood insensitivity (a-insensitivity).

Definition 3 The a-insensitivity index is:

$$
a=1-\left(3 \overline{m_{c}}-3 \overline{m_{s}}\right) .
$$

The a-insensitivity index captures the sensitivity of a decision maker to changes in likelihood within an ambiguous source (e.g. when going from single to composite events). Under perfect sensitivity when the decision maker is ambiguity neutral, the difference between $3 \overline{m_{c}}$ and $3 \overline{m_{s}}$ is exactly 1 , giving $a=0$. The common finding in the literature is that people are a-insensitive and therefore do not differentiate sufficiently between different levels of likelihood. More specifically, they tend to report a relatively low value of $\overline{m_{c}}$ and a relatively high value of $\overline{m_{s}}$, resulting in a positive index $(a>0)$. In the extreme insensitive case when people treat all ambiguous events as fifty-fifty, we have $\overline{m_{s}}=\overline{m_{c}}=0.5$, and therefore $a=1$. The common finding of a-insensitivity can be interpreted as people's misunderstanding of the ambiguous decision situation. People seem to have difficulty understanding different levels of likelihoods, especially for low likelihood events (Zeckhauser and Viscusi 1990).

The ambiguity aversion index and the a-insensitivity index capture two psychologically independent components of ambiguity attitude. The former can be interpreted as emotional, reflecting people's genuine (dis-)like of ambiguous situations, whereas the latter is cognitive, reflecting people's understanding of ambiguous situations. The two components together depict a comprehensive picture of people's ambiguity attitude. Empirically, models with these two components have been shown to have better predicative power than others (Kothiyal et al. 2014). 


\section{Experimental design}

\subsection{Subjects}

The experiment consisted of a rural and an urban session, both run in China. The rural session was in Wuding, one of the poorest counties in Yunan province. Students $\left(n_{1}=89\right.$, average age 17.4) in grade 11 or 12 at Wuding No.1 Middle School, who were receiving financial support from the non-governmental organization "OneSchool" of an amount ranging from $800 \mathrm{RMB}$ to $2000 \mathrm{RMB}^{5}$ per semester, were selected. The urban session was run in Wuhan, the capital city of Hubei province. It is the most populous city in Central China, whose GDP ranked 9th in 2012 nationwide. Two classes of students $\left(n_{2}=91\right.$, average age 16.1) were randomly selected in grade 11 at Donghu Middle School. They mostly came from middle class households.

Both sessions were conducted in November 2013 during regular school hours, with permission from principals and coordinating teachers at the participating schools. No student opted out.

\subsection{Procedure}

The experiment was a paper-pencil based classroom experiment. Both written and oral instructions were provided by the author, with information on the experimental procedure, the payment process, and a typical choice task for illustration.

All subjects in the same session started the experiment at the same time. They faced 36 choice lists, 13 demographic questions, and 5 cognitive reflection questions (Frederick 2005). ${ }^{6}$ After finishing, they raised their hands to notify the experimenter, and were then guided to the payment desk, where each subject played out one of their choices for real. Payments were handled by assistants recruited locally. Original experimental material and its English translation are in the Online Appendix.

\subsection{Stimuli: choice lists}

Figure 1 presents a typical choice list. As explained in Section 2, the ambiguous source was generated by the uncertainty about the true meaning of an unknown phrase. The risky source was generated by a random draw of a number from a box containing 100 tickets numbered from 1 to 100 .

It was explained to the subjects that, for each risky lottery (Lottery A), there was a set of winning numbers. If the random number drawn is one of the winning numbers, the risky lottery pays 40 yuan; otherwise, it pays nothing. Similarly, for each ambiguous lottery (Lottery B), there was a set of winning meanings. If the true meaning of the phrase is one of the winning meanings, the ambiguous lottery pays 40 yuan; otherwise, it pays nothing. By construction, every set of winning numbers

\footnotetext{
${ }^{5}$ The tuition fee for one semester is around RMB 1500 per student, and the lowest sustainable monthly living expense is about RMB 400 per student.

${ }^{6}$ Out of the 5 cognitive reflection questions, three were the original ones from Frederick (2005), and two were designed by the author in the same spirit.
} 


\begin{tabular}{|c|c|c|c|c|}
\hline \multirow{2}{*}{$\begin{array}{c}\text { Question Number } \\
1\end{array}$} & \multicolumn{2}{|c|}{$\begin{array}{c}\text { Lottery A } \\
\text { Winning numbers are: }\end{array}$} & \multicolumn{2}{|c|}{$\begin{array}{c}\text { Lottery B } \\
\text { Winning meanings are: }\end{array}$} \\
\hline & 口 & 0 & 口 & Upward. \\
\hline 2 & 口 & 1. & 口 & Upward. \\
\hline 3 & 口 & 1 and 2. & 口 & Upward. \\
\hline 4 & 口 & $1, \ldots$, and 3 . & 口 & Upward. \\
\hline 5 & 口 & $1, \ldots$, and 4. & 口 & Upward. \\
\hline 6 & 口 & $1, \ldots$, and 5 . & 口 & Upward. \\
\hline 7 & 口 & $1, \ldots$, and 10 & 口 & Upward. \\
\hline 8 & 口 & $1, \ldots$, and 15 & 口 & Upward. \\
\hline 9 & 口 & $1, \ldots$, and 20 & 口 & Upward. \\
\hline 10 & 口 & $1, \ldots$, and 25 & 口 & Upward. \\
\hline 11 & 口 & $1, \ldots$, and 30 & 口 & Upward. \\
\hline 12 & 口 & $1, \ldots$, and 35 & 口 & Upward. \\
\hline 13 & 口 & $1, \ldots$, and 40 & 口 & Upward. \\
\hline 14 & 口 & $1, \ldots$, and 45 & 口 & Upward. \\
\hline 15 & 口 & $1, \ldots$, and 50 & 口 & Upward. \\
\hline 16 & 口 & $1, \ldots$, and 55. & 口 & Upward. \\
\hline 17 & 口 & $1, \ldots$, and 60 & 口 & Upward. \\
\hline 18 & 口 & $1, \ldots$, and 65 . & 口 & Upward. \\
\hline 19 & 口 & $1, \ldots$, and 70 & 口 & Upward. \\
\hline 20 & 口 & $1, \ldots$, and 75 & 口 & Upward. \\
\hline 21 & 口 & $1, \ldots$, and 80 & 口 & Upward. \\
\hline 22 & 口 & $1, \ldots$, and 85 & 口 & Upward. \\
\hline 23 & 口 & $1, \ldots$, and 90 & 口 & Upward. \\
\hline 24 & 口 & $1, \ldots$, and 95 & 口 & Upward. \\
\hline 25 & 口 & $1, \ldots$, and 96 & 口 & Upward. \\
\hline 26 & 口 & $1, \ldots$, and 97 & 口 & Upward. \\
\hline 27 & 口 & $1, \ldots$, and 98 & 口 & Upward. \\
\hline 28 & 口 & $1, \ldots$, and 99 & 口 & Upward. \\
\hline 29 & 口 & $1, \ldots$ and 100 . & 口 & Upward. \\
\hline
\end{tabular}

Fig. 1 An example of a choice list

corresponds to a winning probability, whereas every set of winning meanings corresponds to an ambiguous event.

In each line of the choice list, subjects specified which one of the two lotteries they preferred. Within the same choice list, risky lotteries became better as the total number of valid winning numbers (the number 0 in the first row of the choice list is not a valid winning number) increased, while the ambiguous lottery stayed the same. Across different choice lists, the ambiguous events differed. Subjects who satisfied monotonicity preferred the ambiguous lottery when the winning probability of the risky lottery was small, and preferred the risky lottery when the winning probability was big enough. The midpoint of the two lines where their preference switched was taken as their matching probability.

Six phrases from the Beijing dialect (BJ) of Chinese, the Shanghai dialect $(\mathrm{SH})$ of Chinese, Japanese (JP), English (EN), Korean (KR), and Dutch (NL), respectively, were used. The phrases were chosen so that the vast majority of the subjects would not know their true meanings in Chinese. All phrases were presented in the original 
language. ${ }^{7}$ For each phrase, six choice lists were used to elicit the matching probabilities of all six events. In total, there were thirty-six choice lists. All subjects received the same thirty-six choice lists but in three different orders. ${ }^{8}$

\subsection{Incentives}

Every subject received a show-up fee of $20 \mathrm{RMB}$ and, in addition, played out one of the choices for real using the procedure described below. Each experimental session (including instruction and payment) lasted about one hour. The average payment (including show-up fee) was $41 \mathrm{RMB}$ in the rural session and $42 \mathrm{RMB}$ in the urban session.

Choices in the experiment were incentivized using a random incentive system. At the end of the experiment, each subject first drew two numbers, and then played out his choice for real in the corresponding line in the corresponding choice list determined by these two numbers.

\section{Results}

In total, $5 \%$ of the subjects (7 in the rural session and 2 in the urban session) had incomplete choice lists ( $2 \%$ of all choice lists). These choices were recorded as missing.

\subsection{Multiple switching}

In the rural session, $26.8 \%$ of the choices had multiple switching points; while the percentage is $4.6 \%$ in the urban session. ${ }^{9}$ The rate of multiple switching is higher in the rural session than in the urban session $(p<0.01)$. In the analyses reported in the main text, choices with multiple switching points were excluded. After exclusion, 151 subjects remained. These exclusions do not affect the main results (Appendix B).

Multiple switching points entail a violation of monotonicity. Understanding the decision tasks and behaving in accordance with the monotonicity principle requires cognitive ability. Comparing the performance of the urban and rural adolescents in Frederick's cognitive reflection test, the urban group answered on average $70 \%$ of the questions correctly, while the rate of correct responses was only $40 \%$ in the rural group. ${ }^{10}$ The negative correlation $(-0.215, p<0.01)$ between the cognitive

\footnotetext{
${ }^{7}$ The Japanese phrase was presented in its Kanji form. These Kanji characters are also meaningful characters in modern Chinese.

${ }^{8}$ Three different orders were used: (BJ, SH, JP, EN, KR, NL); (JP, EN, KR, NL, BJ, SH); and (KR, NL, BJ, SH, JP, EN).

${ }^{9}$ Field data commonly contains more noise than controlled lab data. See Section 4 of Dimmock et al. (2016b) for a discussion.

${ }^{10} \mathrm{We}$ also looked at the rate of correct response to the 3 original cognitive reflection test questions. The mean CRT score was 2.1 for urban students, which is slightly lower than MIT students and much higher than Princeton students reported in Frederick (2005). The rural students scored 1.08, which is lower than students from University of Michigan: Ann Harbor, but higher than Bowling Green University.
} 
reflection test score and the number of multiple switching points suggests that lower cognitive ability results in more irrational choices.

\subsection{Matching probabilities}

Figure 2 shows the boxplots of single event matching probabilities. The light bar represents the matching probabilities of the true events. Subjects were not always equally willing to bet on the three events. For instance, for the Shanghai dialect, subjects were more willing to bet on the true event than for the other two events. Kruskal-Wallis tests showed that matching probabilities for the three events were not equal for the Shanghai dialect, the Beijing dialect, Japanese, and Korean ( $p<$ $0.01, p=0.014, p<0.01$, and $p<0.01$, respectively). But this was not the case for the two western languages: English and Dutch $(p=0.20$ and $p=0.17$ respectively). Since these matching probabilities capture subjects' subjective beliefs (although distorted by their ambiguity attitudes) about each event happening, it shows that subjects had stronger opinions about one event being true (or untrue) for Asian languages, even though they may not always be right - for instance, in the case of Korean.

The asymmetry in beliefs for Asian languages shows that the often assumed symmetry in beliefs in experiments with artificial ambiguity sources does not hold in this
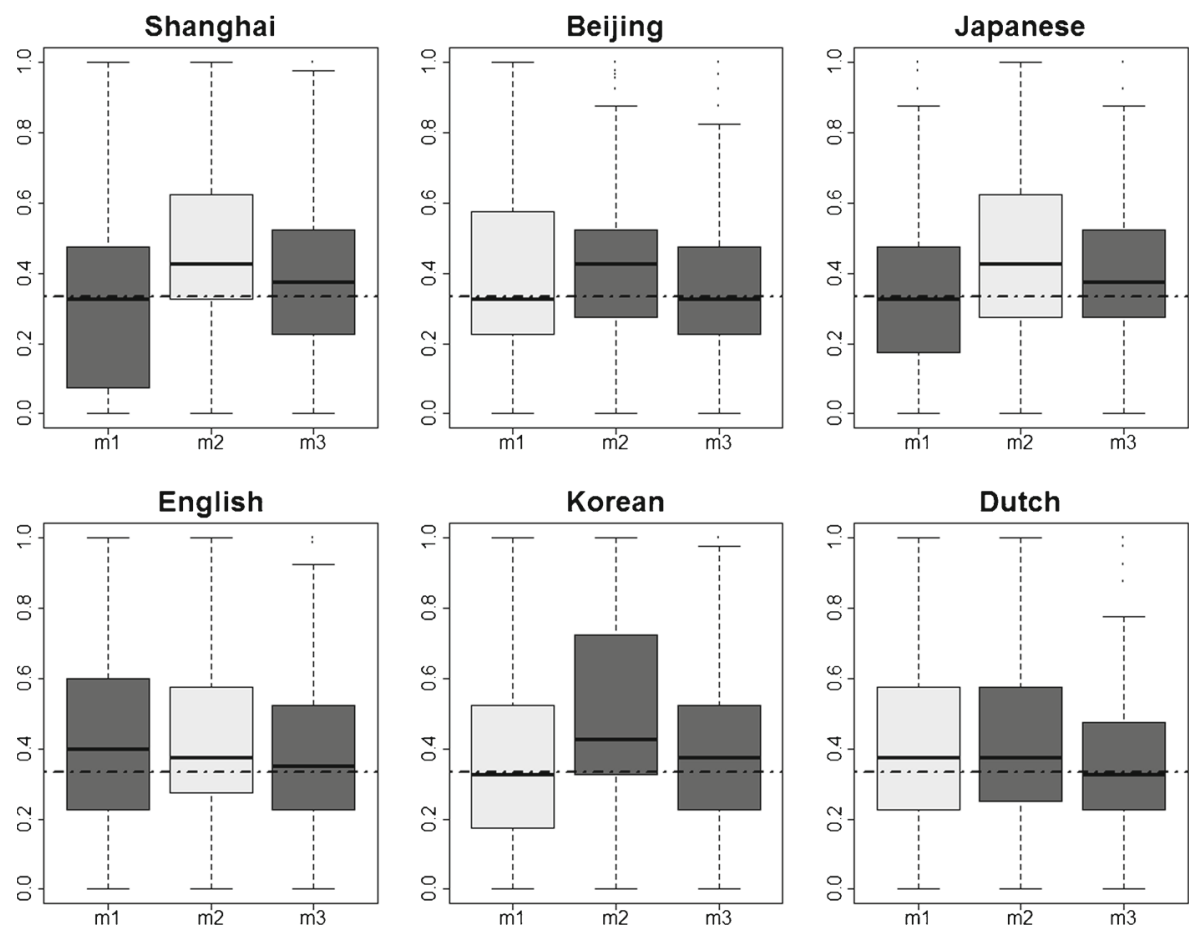

Fig. 2 Boxplots of single event matching probabilities. The light grey box indicates the true event. Horizontal dashed lines indicate $p=1 / 3$ 
experiment. The ambiguity attitudes measurements in this paper are, however, not affected by such violations as the Baillon et al. (2017b) method adopted here provides control for beliefs without the need for the symmetry assumption. Summary statistics of the matching probabilities, the two ambiguity attitude indices, and other demographic variables are in Table 1.

\subsection{Income effect within the urban and the rural sample}

Within each group, the income variation is big (see Table 1), but adolescents are expected to be rather homogeneous on unobserved factors, such as parents' education

Table 1 Summary statistics

\begin{tabular}{|c|c|c|c|c|c|c|c|c|c|c|}
\hline & \multicolumn{5}{|l|}{ Urban } & \multicolumn{5}{|l|}{ Rural } \\
\hline & Mean & Med. & Std & Min & Max & Mean & Med. & Std & Min & $\operatorname{Max}$ \\
\hline$m_{1}$ & 0.36 & 0.32 & 0.27 & 0.00 & 1.00 & 0.39 & 0.32 & 0.27 & 0.00 & 1.00 \\
\hline$m_{2}$ & 0.49 & 0.42 & 0.29 & 0.00 & 1.00 & 0.41 & 0.38 & 0.26 & 0.00 & 1.00 \\
\hline$m_{3}$ & 0.38 & 0.38 & 0.26 & 0.00 & 1.00 & 0.39 & 0.38 & 0.25 & 0.00 & 1.00 \\
\hline$m_{12}$ & 0.65 & 0.62 & 0.25 & 0.00 & 1.00 & 0.58 & 0.58 & 0.27 & 0.00 & 1.00 \\
\hline$m_{23}$ & 0.64 & 0.62 & 0.26 & 0.00 & 1.00 & 0.55 & 0.52 & 0.26 & 0.00 & 1.00 \\
\hline$m_{13}$ & 0.55 & 0.58 & 0.29 & 0.00 & 1.00 & 0.58 & 0.58 & 0.27 & 0.00 & 1.00 \\
\hline$\overline{m_{s}}$ & 0.41 & 0.38 & 0.17 & 0.00 & 0.96 & 0.40 & 0.38 & 0.20 & 0.00 & 1.00 \\
\hline$\overline{m_{c}}$ & 0.61 & 0.64 & 0.18 & 0.00 & 1.00 & 0.57 & 0.57 & 0.21 & 0.00 & 1.00 \\
\hline$b$ & 0.02 & 0.00 & 0.29 & -1.00 & 0.81 & -0.05 & -0.07 & 0.32 & -1.00 & 1.00 \\
\hline$a$ & -0.38 & -0.40 & 0.53 & -2.00 & 2.00 & -0.50 & -0.55 & 0.55 & -3.96 & 1.53 \\
\hline age & 16.14 & 16.00 & 0.55 & 15.00 & 18.00 & 17.42 & 17.50 & 0.81 & 15.00 & 19.00 \\
\hline male & 0.45 & 0.00 & 0.50 & 0.00 & 1.00 & 0.35 & 0.00 & 0.48 & 0.00 & 1.00 \\
\hline income & 1.06 & 0.80 & 1.30 & 0.10 & 8.00 & 0.10 & 0.08 & 0.09 & 0.01 & 0.70 \\
\hline tv & 0.90 & 1.00 & 0.30 & 0.00 & 1.00 & 0.97 & 1.00 & 0.18 & 0.00 & 1.00 \\
\hline internet & 0.99 & 1.00 & 0.11 & 0.00 & 1.00 & 0.01 & 0.00 & 0.11 & 0.00 & 1.00 \\
\hline no.sib & 0.46 & 0.00 & 0.83 & 0.00 & 4.00 & 1.10 & 1.00 & 0.59 & 0.00 & 5.00 \\
\hline grade & 68.33 & 67.78 & 5.60 & 54.11 & 82.22 & 64.98 & 64.89 & 8.12 & 46.89 & 85.78 \\
\hline fav.lan & 0.47 & 0.00 & 0.50 & 0.00 & 1.00 & 0.60 & 1.00 & 0.49 & 0.00 & 1.00 \\
\hline crt & 0.70 & 0.60 & 0.22 & 0.00 & 1.00 & 0.44 & 0.40 & 0.28 & 0.00 & 1.00 \\
\hline
\end{tabular}

This table presents summary statistics of the following variables: $m_{i}, i \in\{1,2,3\}$ are the matching probabilities for single events; $m_{i j}$ are matching probabilities for the corresponding composite events; $\overline{m_{s}}$ : average matching probability of single events; $\overline{m_{c}}$ : average matching probability of composite events; $b$ : index of ambiguity aversion; $a$ : index of a-insensitivity; age; male: a dummy variable taking value 1 if male; household income in 10,000RMB; tv: a dummy variable taking value 1 if the subject has a TV set at home; internet: a dummy variable taking value 1 if the subject has a computer with internet access; no.sib: number of siblings; grade: average grades in the latest exam as percentage of maximum grade; fav.lan (language as favorite course): dummy variable taking value 1 if the subject stated Chinese or English (or both) as two of his favorite courses at school in the questionnaire; and crt: the percentage of correct answers in the cognitive reflection test 

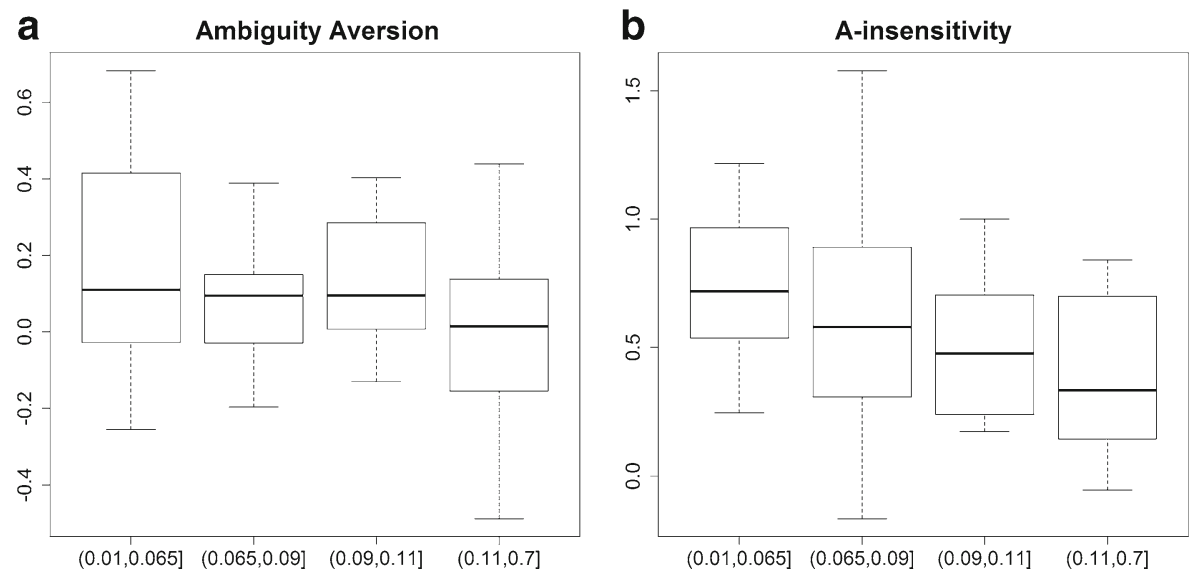

Fig. 3 Boxplots of ambiguity attitude indices for rural subjects in each income quartile

and access to information. For instance, almost everyone in the urban group and almost no one in the rural group reported having access to the internet. ${ }^{11}$

Figure 3 (Fig. 4) shows the boxplot of the two ambiguity attitude indices for rural (urban) subjects in each income quartile. A decreasing trend is observed for rural subjects for ambiguity aversion and a-insensitivity. For the urban subjects, no clear trend is observed for ambiguity aversion and a slightly increasing trend is observed for a-insensitivity.

Table 2 reports regression results of ambiguity attitude indices on demographic variables for rural and urban adolescents separately. Standard errors are clustered at the individual level to control for potential correlation of observations from the same subject. Odd-numbered models included only household income (total household income of the core family in 10,000 RMB) as an explanatory variable, whereas even numbered models included other demographic variables such as gender (male $=1$ if male), age, number of siblings (no.sib), their performance in the cognitive reflection test (crt), their performance in the most recent exam at school (grade), whether they listed language courses as their favorite courses at school (fav.lan = 1), and their ranking (1 to 6) of the six dialects/language according to their familiarity (rank), where a higher rank corresponds with a less familiar language.

Table 3 reports regression results with the urban and rural data pooled together where interactions of all variables with the urban dummy are included. The coefficients of the interaction terms show whether the demographic variables have different impacts on ambiguity attitudes for rural than the urban adolescents.

Income has a negative effect (marginally significant) on ambiguity aversion for rural adolescents. It becomes more significant after controlling for other demographic

\footnotetext{
${ }^{11}$ This variable is not included in the regression due to lack of variance within group, and because it is almost perfectly correlated with the location variable.
} 

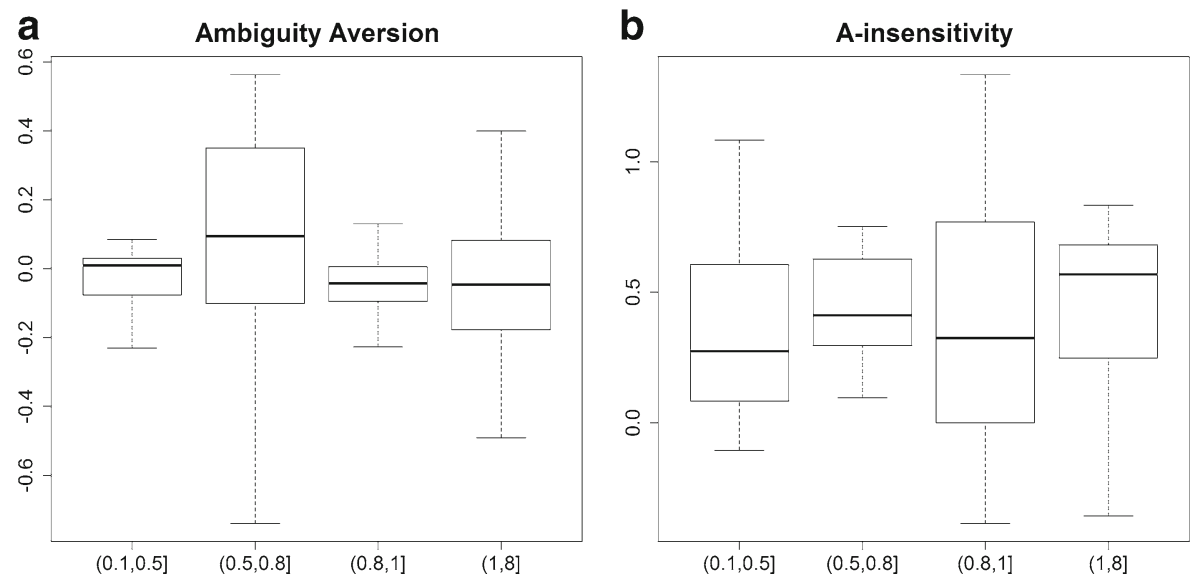

Fig. 4 Boxplots of ambiguity attitude indices for urban subjects in each income quartile

variables. However, it has no impact on the urban adolescents' ambiguity aversion. ${ }^{12}$ The significant interaction effect of urban and income (Table 3) confirms that the negative income effect on ambiguity aversion is weaker for urban adolescents than for their rural counterparts. As for income effect on a-insensitivity, it is negative for rural adolescents but positive for the urban adolescents. ${ }^{13}$ Both effects remain significant after controlling for other demographic variables. Regression results in Tables 2 and 3 show that income has an opposite impact on a-insensitivity for urban adolescents than for their rural counterparts.

There is no gender difference and only a weak age effect on ambiguity aversion for urban adolescents. Number of siblings does not have any impact on people's ambiguity attitudes. Rural adolescents who score high in tests at school are more ambiguity seeking, and urban adolescents with higher grades are more a-insensitive. What is more, the familiarity ranking has a positive impact on rural adolescents' ainsensitivity, suggesting that rural adolescents tend to be more sensitive to sources that they are more familiar with. Lastly, rural adolescents who listed English or Chinese (or both) as their favorite courses at school tend to be more a-insensitive, and this effect is not significant among urban adolescents.

\subsection{Ambiguity attitudes: Rural and urban comparison}

This section compares ambiguity attitudes between the two groups of Chinese adolescents.

\footnotetext{
${ }^{12}$ In the pooled regressions (Table 3), the net income effect on urban adolescents' ambiguity aversion is the same as the effect reported in Table 2: -0.018 (standard error: 0.017) in model (1) and - 0.022 (standard error: 0.014) in model (2). Income has no significant effect on ambiguity aversion in the urban group.

${ }^{13}$ In the pooled regression (Table 3), the net income effect on urban adolescents' a-insensitivity is the same as the effect reported in Table 2: 0.046 (standard error: 0.014) in model (3) and 0.069 (standard error: 0.019 ) in model (4). It has a positive effect on a-insensitivity in the urban group.
} 
Table 2 Ambiguity attitudes: Urban and rural separate

\begin{tabular}{|c|c|c|c|c|c|c|c|c|}
\hline & \multicolumn{4}{|c|}{ Ambiguity aversion } & \multicolumn{4}{|c|}{ A-insensitivity } \\
\hline & \multicolumn{2}{|l|}{ Rural } & \multicolumn{2}{|l|}{ Urban } & \multicolumn{2}{|l|}{ Rural } & \multicolumn{2}{|l|}{ Urban } \\
\hline & (1) & (2) & (3) & (4) & (5) & (6) & (7) & (8) \\
\hline income & $\begin{array}{l}-0.609^{*} \\
(0.322)\end{array}$ & $\begin{array}{l}-0.505^{* *} \\
(0.243)\end{array}$ & $\begin{array}{l}-0.018 \\
(0.017)\end{array}$ & $\begin{array}{l}-0.022 \\
(0.017)\end{array}$ & $\begin{array}{l}-1.167^{* * *} \\
(0.294)\end{array}$ & $\begin{array}{l}-1.391^{* * *} \\
(0.308)\end{array}$ & $\begin{array}{l}0.046^{* * *} \\
(0.014)\end{array}$ & $\begin{array}{l}0.069^{* * *} \\
(0.019)\end{array}$ \\
\hline male & & $\begin{array}{l}-0.018 \\
(0.077)\end{array}$ & & $\begin{array}{l}0.004 \\
(0.072)\end{array}$ & & $\begin{array}{l}-0.012 \\
(0.093)\end{array}$ & & $\begin{array}{l}0.044 \\
(0.122)\end{array}$ \\
\hline age & & $\begin{array}{l}0.012 \\
(0.047)\end{array}$ & & $\begin{array}{l}-0.076^{*} \\
(0.043)\end{array}$ & & $\begin{array}{l}-0.006 \\
(0.047)\end{array}$ & & $\begin{array}{l}0.123 \\
(0.082)\end{array}$ \\
\hline no.sib & & $\begin{array}{l}-0.040 \\
(0.055)\end{array}$ & & $\begin{array}{l}-0.027 \\
(0.039)\end{array}$ & & $\begin{array}{l}0.055 \\
(0.098)\end{array}$ & & $\begin{array}{l}-0.030 \\
(0.108)\end{array}$ \\
\hline crt & & $\begin{array}{l}0.021 \\
(0.150)\end{array}$ & & $\begin{array}{l}-0.197 \\
(0.140)\end{array}$ & & $\begin{array}{l}-0.254 \\
(0.166)\end{array}$ & & $\begin{array}{l}0.247 \\
(0.214)\end{array}$ \\
\hline grade & & $\begin{array}{l}-0.008^{* *} \\
(0.004)\end{array}$ & & $\begin{array}{l}0.001 \\
(0.005)\end{array}$ & & $\begin{array}{l}0.007 \\
(0.005)\end{array}$ & & $\begin{array}{l}0.018^{* *} \\
(0.009)\end{array}$ \\
\hline fav.lan & & $\begin{array}{l}-0.028 \\
(0.085)\end{array}$ & & $\begin{array}{l}-0.012 \\
(0.077)\end{array}$ & & $\begin{array}{l}0.225^{* *} \\
(0.089)\end{array}$ & & $\begin{array}{l}-0.016 \\
(0.124)\end{array}$ \\
\hline rank & & $\begin{array}{l}0.008 \\
(0.007)\end{array}$ & & $\begin{array}{l}0.003 \\
(0.006)\end{array}$ & & $\begin{array}{l}0.033^{* *} \\
(0.015)\end{array}$ & & $\begin{array}{l}0.008 \\
(0.011)\end{array}$ \\
\hline Constant & $\begin{array}{l}0.136^{* *} \\
(0.053)\end{array}$ & $\begin{array}{l}0.506 \\
(0.882)\end{array}$ & $\begin{array}{l}0.0003 \\
(0.046)\end{array}$ & $\begin{array}{l}1.303 \\
(0.880)\end{array}$ & $\begin{array}{l}0.651^{* * *} \\
(0.063)\end{array}$ & $\begin{array}{l}0.088 \\
(0.894)\end{array}$ & $\begin{array}{l}0.308^{* * *} \\
(0.069)\end{array}$ & $\begin{array}{l}-3.167^{*} \\
(1.641)\end{array}$ \\
\hline Observations & 269 & 261 & 342 & 341 & 269 & 261 & 342 & 341 \\
\hline $\mathrm{R}^{2}$ & 0.040 & 0.100 & 0.007 & 0.047 & 0.051 & 0.137 & 0.012 & 0.049 \\
\hline
\end{tabular}

Explanation of the number of observations: for each subject, to calculate his ambiguity attitude indices to an ambiguous source, it is necessary that he does not have multiple switching in all six choice lists for that source. If multiple switching occurs in one of the six choice lists, his choices concerning the ambiguity source will be excluded. His choices concerning other ambiguity sources can still be included as long as there are no multiple switching in those choice lists. For some subjects, some demographic information is missing. In the regression models, only observations with all variables available are included ${ }^{*} \mathrm{p}<0.1 ;{ }^{* *} \mathrm{p}<0.05 ;{ }^{* * *} \mathrm{p}<0.01$. Robust standard errors clustered at the individual level

Ambiguity aversion index Figure 5a depicts the mean value of the ambiguity aversion indices for different sources and an average index for all sources. Overall, urban adolescents had negative ambiguity aversion ( $p=0.02$ in a two-sided Wilcoxon signed-rank test), exhibiting ambiguity seeking; whereas rural adolescents exhibited ambiguity aversion $(p<0.01)$. Accordingly, the urban adolescents had a higher ambiguity aversion than the rural adolescents $(p<0.01)$. Across different sources generated by the six phrases, there is no difference in ambiguity aversion across sources $\left(\chi^{2}(5)=5.41, p=0.37\right.$ in Friedman test). 
Table 3 Urban and rural pooled with interaction terms

\begin{tabular}{|c|c|c|c|c|}
\hline & \multicolumn{4}{|c|}{ Dependent variable: } \\
\hline & \multicolumn{2}{|c|}{ Ambiguity aversion } & \multicolumn{2}{|c|}{ A-insensitivity } \\
\hline & (1) & (2) & (3) & (4) \\
\hline \multirow[t]{2}{*}{ urban } & $-0.136^{*}$ & 0.797 & $-0.343^{* * *}$ & $-3.255^{*}$ \\
\hline & $(0.070)$ & $(1.246)$ & $(0.094)$ & $(1.869)$ \\
\hline \multirow[t]{2}{*}{ income } & $-0.609^{*}$ & $-0.505^{* *}$ & $-1.167^{* * *}$ & $-1.391^{* * *}$ \\
\hline & $(0.322)$ & $(0.243)$ & $(0.294)$ & $(0.308)$ \\
\hline \multirow[t]{2}{*}{ male } & & -0.018 & & -0.012 \\
\hline & & $(0.077)$ & & $(0.093)$ \\
\hline \multirow[t]{2}{*}{ age } & & 0.012 & & -0.006 \\
\hline & & $(0.047)$ & & $(0.047)$ \\
\hline \multirow[t]{2}{*}{ no.sib } & & -0.040 & & 0.055 \\
\hline & & $(0.055)$ & & $(0.098)$ \\
\hline \multirow[t]{2}{*}{ crt } & & 0.021 & & -0.254 \\
\hline & & $(0.150)$ & & $(0.166)$ \\
\hline \multirow[t]{2}{*}{ grade } & & $-0.008^{* *}$ & & 0.007 \\
\hline & & $(0.004)$ & & $(0.005)$ \\
\hline \multirow[t]{2}{*}{ fav.lan } & & -0.028 & & $0.225^{* *}$ \\
\hline & & $(0.085)$ & & $(0.089)$ \\
\hline \multirow[t]{2}{*}{ rank } & & 0.008 & & $0.033^{* *}$ \\
\hline & & $(0.007)$ & & $(0.015)$ \\
\hline \multirow[t]{2}{*}{ urban:income } & $0.591^{*}$ & $0.483^{* *}$ & $1.213^{* * *}$ & $1.460^{* * *}$ \\
\hline & $(0.322)$ & $(0.244)$ & $(0.294)$ & $(0.309)$ \\
\hline \multirow[t]{2}{*}{ urban:male } & & 0.022 & & 0.055 \\
\hline & & $(0.106)$ & & $(0.154)$ \\
\hline \multirow[t]{2}{*}{ urban:age } & & -0.088 & & 0.128 \\
\hline & & $(0.064)$ & & $(0.094)$ \\
\hline \multirow[t]{2}{*}{ urban:no.sib } & & 0.013 & & -0.085 \\
\hline & & $(0.068)$ & & $(0.146)$ \\
\hline \multirow[t]{2}{*}{ urban:crt } & & -0.218 & & $0.501^{*}$ \\
\hline & & $(0.205)$ & & $(0.271)$ \\
\hline \multirow[t]{2}{*}{ urban:grade } & & 0.009 & & 0.011 \\
\hline & & $(0.007)$ & & $(0.010)$ \\
\hline \multirow[t]{2}{*}{ urban:fav.lan } & & 0.016 & & -0.241 \\
\hline & & $(0.115)$ & & $(0.152)$ \\
\hline \multirow[t]{2}{*}{ urban:rank } & & -0.005 & & -0.025 \\
\hline & & $(0.009)$ & & $(0.018)$ \\
\hline \multirow[t]{2}{*}{ Constant } & $0.136^{* *}$ & 0.506 & $0.651^{* * *}$ & 0.088 \\
\hline & $(0.053)$ & $(0.882)$ & $(0.063)$ & $(0.894)$ \\
\hline Observations & 611 & 602 & 611 & 602 \\
\hline $\mathrm{R}^{2}$ & 0.040 & 0.100 & 0.048 & 0.102 \\
\hline
\end{tabular}

${ }^{*} \mathrm{p}<0.1 ;{ }^{* *} \mathrm{p}<0.05 ;{ }^{* * *} \mathrm{p}<0.01$. Robust standard errors clustered at the individual level 

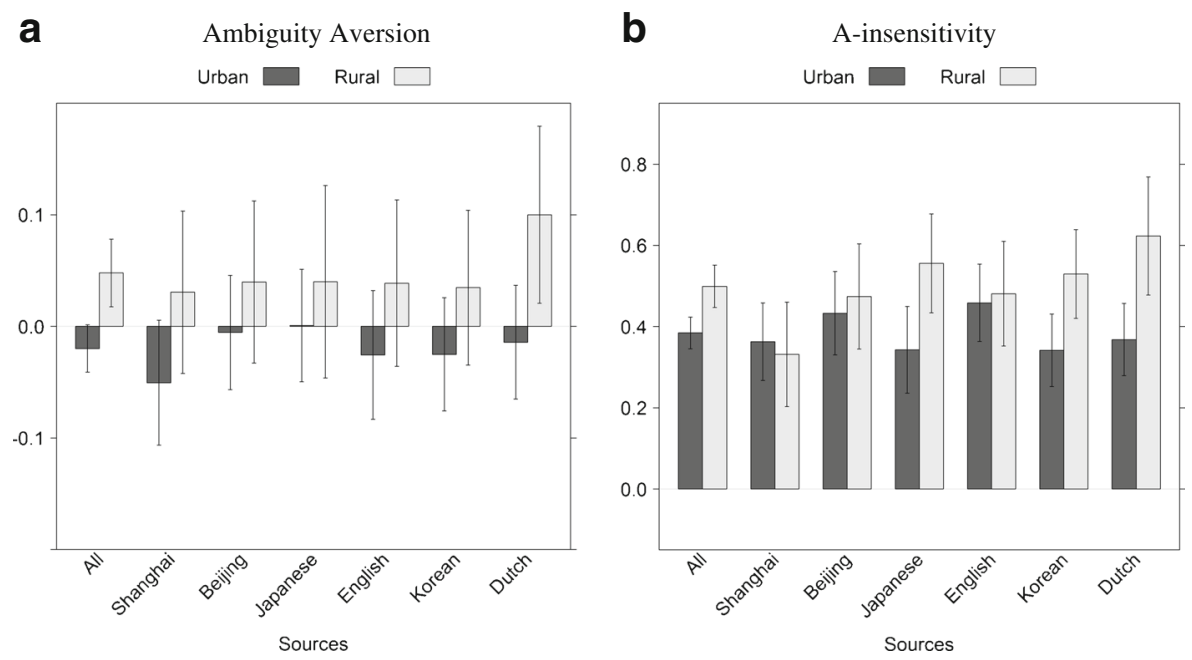

Fig. 5 Means of ambiguity attitude indices. Error bars indicate the $90 \%$ confidence interval

A-insensitivity index Figure $5 b$ depicts the mean value of the a-insensitivity indices. Both urban and rural adolescents had positive a-insensitivity indices (all p-values $<0.01$ in two-sided Wilcoxon signed-rank tests), exhibiting substantial insensitivity to changes in different levels of likelihood. Rural adolescents were less sensitive to changes in likelihood than urban adolescents $(p<0.01$ in a two-sided Wilcoxon rank-sum test). Comparing subjects' a-insensitivity in different sources, there is no difference $\left(\chi^{2}(5)=5.72, p=0.33\right.$, in Friedman test).

The between-group tests in Section 4.4 treat all observations as independent. In Section 4.5, a non-linear random coefficient model is estimated to check for robustness while allowing for potential correlation of observations from the same subject. All significant differences remain significant.

As in other studies, factors other than income may have contributed to the difference in ambiguity attitudes between the two groups. To provide more insight into the contribution of income to the observed differences in ambiguity attitudes, the full sample is divided into two parts: one subsample with only adolescents from households whose income is between the minimum of the urban group and the maximum of the rural group - where the two groups' income overlap, and the rest form the other subsample. The subsample with income overlap consists of 52 subjects (out of 151 after excluding subjects with multiple switching), where 28 come from the urban group.

Figure 6 presents the comparison between urban and rural subjects in the two subsamples. The urban rural difference in ambiguity aversion is smaller in the subsample with overlap than in the subsample without $(p=0.05$ for the interaction effect of urban and overlap ${ }^{14}$ in ANOVA). The same holds for a-insensitivity $(p<0.01)$.

\footnotetext{
${ }^{14}$ Overlap is a dummy variable that takes value 1 if the observation comes from the subsample with income overlap.
} 

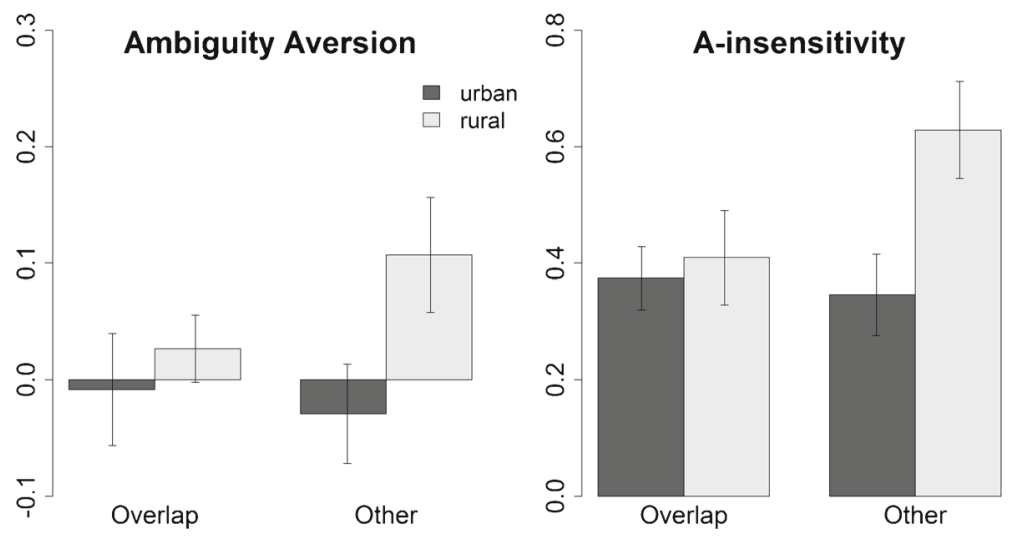

Fig. 6 Means of ambiguity attitude indices for sub-sample and for the rest. Error bars indicate the $90 \%$ confidence interval

This shows that differences in income have contributed to the observed rural-urban differences in ambiguity attitudes.

\subsection{Robustness}

To account for errors, a non-linear random coefficient model with Fechner errors (Becker et al. 1963; Hey and Orme 1994) is used. This model estimates the distribution of the individual-specific ambiguity attitude indices and subjective probabilities with pooling data (Appendix A).

The estimation results assuming stochastic preferences are similar to the regression results in Table 3. Coefficients differ slightly, but all the main patterns remain: the urban adolescents were more ambiguity seeking and less insensitive to likelihood changes than their rural counterpart on average. The findings on the relationship between income and ambiguity attitudes within each group also remain.

\section{Discussion}

This paper investigates the relationship between income and people's ambiguity attitudes among two groups of Chinese adolescents. Table 4 gives a summary of prior studies on people's ambiguity attitudes in the developing world. These studies on ambiguity attitudes in the developing world focused on the implications of people's ambiguity attitudes on their real life decisions. Most of them found people to be ambiguity averse. In the current study, the poor rural adolescents were ambiguity averse. However, the rich urban adolescents were ambiguity seeking. Given the vast literature suggesting that ambiguity aversion is universal, the finding of urban adolescents being ambiguity seeking may seem surprising. However, many recent studies have shown that ambiguity seeking is more common than traditionally thought (Chesson 
Table 4 Prior literature summary

\begin{tabular}{|c|c|c|c|c|}
\hline Paper & Location & $\begin{array}{l}\text { Ambiguity } \\
\text { Aversion }\end{array}$ & $\begin{array}{l}\text { Income/Wealth } \\
\text { Effect on AA }\end{array}$ & $\begin{array}{l}\text { More AA } \\
\text { people are: }\end{array}$ \\
\hline Akay et al. (2012) & Ethiopia & AA & $\begin{array}{l}\text { No (land size; } \\
\text { consumption) }\end{array}$ & - \\
\hline Alpizar et al. (2011) & Costa Rica & $\mathrm{AA}^{\mathrm{a}}$ & - & $\begin{array}{l}\text { more } \\
\text { willingness to } \\
\text { insure }\end{array}$ \\
\hline $\begin{array}{l}\text { Cardenas and Carpenter } \\
\text { (2013) }\end{array}$ & Latin America ${ }^{b}$ & AA & $\begin{array}{l}\text { No (number of } \\
\text { income earner; } \\
\text { home size) }\end{array}$ & less happy \\
\hline $\begin{array}{l}\text { Engle-Warnick et al. } \\
\text { (2011) }\end{array}$ & Peru & AA & No (land size) & $\begin{array}{l}\text { less likely to } \\
\text { diversify crop } \\
\text { varieties }\end{array}$ \\
\hline Ross et al. (2012) & Lao PDR & AN & - & $\begin{array}{l}\text { less likely to } \\
\text { adopt new } \\
\text { crops }\end{array}$ \\
\hline
\end{tabular}

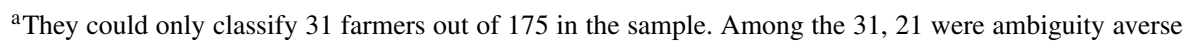
and the other 10 were either neutral or seeking

${ }^{\mathrm{b}}$ The study was conducted in six capital cities in Latin America: Bogotá, Buenos Aires, Caracas, Lima, Montevideo, and San José

and Viscusi 2003; Binmore et al. 2012; Trautmann and van de Kuilen 2015; Kocher et al. 2015).

The current study is the first to measure a-insensitivity in the developing world. Both urban and rural Chinese adolescents are a-insensitive, but the rural adolescents are more so. Measuring and understanding a-insensitivity is of special interest for studying developmental issues, as a better understanding of people's behavioral biases can provide guidance on designs of more effective interventions. For instance, there has been a persistent under-adoption of bed net ${ }^{15}$ in low income countries, even though its benefit in malaria prevention has been shown to be substantial. Ainsensitivity can provide an explanation and accordingly policy intervention for this issue. Considering an extremely a-insensitive person, as long as the bed net does not fully eliminate the chances of getting infected, he will not be willing to invest in such a prevention because uncertainty reduction without elimination is immaterial to him. For such a person, the often used intervention through social influence would not work because one single case of infection after adoption of bed net will demotivate him from purchasing. For a less extreme person, the effect is not so dramatic but the under-evaluation is still present. If a-insensitivity affects people's willingness to take up preventive measures, then interventions that aim to reduce a-insensitivity can improve their effectiveness.

\footnotetext{
${ }^{15} \mathrm{~A}$ bed net is a net hung around the bed that provides protection against diseases often carried by insects, such as mosquitos.
} 
Previous studies on the relationship between income/wealth and people's ambiguity attitudes found little or no evidence (Table 4). This study showed an interesting reversal income effect on ambiguity attitudes. Among the rural adolescents, the poorer are more ambiguity averse and a-insensitive. However, among the urban adolescents, the richer are more a-insensitive. This reversal suggests a non-linear dependence of people's ambiguity attitudes on household income, and the impact is much higher when income is low than when it is high. One possible explanation is that lives of the extremely poor (rich) life are almost surely bad (good), whereas for those in the middle, their own abilities and efforts may open up opportunities to change their future life perspectives. Therefore, adolescents from families with moderate income are more motivated in developing their own capabilities, including their abilities in dealing with ambiguity.

For the poorer rural group, the finding that an increase in income may lead to a decrease in ambiguity aversion and a-insensitivity sheds new light on the problem of the poverty trap. Previous studies in the developing world have shown that more ambiguity averse people are more likely to over-insure, less likely to diversify crop variety, and less likely to adopt new technologies (Table 4). Although only a few empirical studies in the developed world (Dimmock et al. 2016b) and none in the developing world investigated how a-insensitivity impacts people's real life decisions, as argued before, a-insensitivity is commonly believed to be a cognitive bias that underlies many suboptimal decisions. The poorer subjects in the rural group are the extremely poor people, for whom every suboptimal decision that they make further traps them in poverty. Mani et al. (2013) noted that: "being poor means coping not just with a shortfall of money, but also with a concurrent shortfall of cognitive resources. The poor, in this view, are less capable not because of inherent traits, but because the very context of poverty imposes load and impedes cognitive capacity." If the relationship found in this study between income and ambiguity attitudes is causal, it then suggests that financial aid provided to the extremely poor will, among others, substantially help them improve their decisions made under ambiguity.

Methodologically, this paper contributes to ambiguity theory by demonstrating how the Baillon et al. (2017b) method can be easily adapted to study different natural ambiguity sources. For field studies, making the experimental tasks comprehensible to the usually non-academic subject pool has been one major challenge in experimental design. This paper enhances subjects' comprehension of experimental tasks by using a decision context that is similar to what they often encounter in real life. None of the subjects had prior experience in participating in economic experiments. Given the special attention paid by the Chinese culture to education, both groups of subjects spent an enormous amount (from $7 \mathrm{am}$ till 8pm, six days a week) of time at school studying. Their knowledge outside of school life is therefore limited. The language questions were not very different than the English exercises at school, and the lotteries were presented as a coupon lottery that they sometimes play during the new year celebration at school. Hence, the experimental tasks in this study were adapted to be as comprehensible as possible for the subjects.

The finding of no gender difference in ambiguity attitudes was consistent with previous findings (Borghans et al. 2009; Sutter et al. 2013). Rural adolescents with better 
school performance were more ambiguity seeking. This differs from the findings in Sutter et al. (2013), where Austrian children and adolescents with better German grades were more ambiguity averse. On the other hand, for urban adolescents, those with better school performance were more a-insensitive. As the current study is the first to measure a-insensitivity among adolescents, it is hard to compare this finding with prior studies. Overall, the findings on the relationship between school performance and ambiguity attitudes were mixed. More empirical investigations are needed to better understand this issue.

Rural adolescents are less a-insensitive to sources that they perceived to be more familiar with. This agrees with the competence effect, i.e. the positive impact of perceived competence on a-insensitivity (Heath and Tversky 1991; Kilka and Weber 2001). Further, the positive relationship between expressed interest in learning language (listing language courses as favorite) and a-insensitivity has implications for the cultivation and maintenance of an interest in language learning. Affection towards the sources of uncertainty influences decision makers' ambiguity attitudes. Rottenstreich and Hsee (2001) found that subjects were less source sensitive about affect-rich than affect-poor outcomes. In this paper, the finding of less likelihood sensitivity to affect-rich uncertainty sources among the rural adolescents may be due to their psychological fragility. The realization of their limited knowledge in what they thought they were good at makes them less confident, leading to conservatism when expressing probabilistic judgments. As a result, they act taking uncertainties as fifty-fifty, inducing a-insensitivity.

\section{Conclusion}

This paper shows how modern ambiguity models give new insights into linguistics, development economics, and inequality. The relationships between income and the two most relevant components of ambiguity attitude (aversion and insensitivity) were studied among two groups of Chinese adolescents. Among the poorer rural Chinese adolescents, those from households with higher income were both less ambiguity averse and a-insensitive, whereas among the richer urban adolescents, ambiguity aversion was not related to income but a-insensitivity increased with income. Comparing the two groups, the (urban) rich are less ambiguity averse and insensitive to ambiguity than their (rural) poor counterparts. Among the rural poor, ambiguity aversion and a-insensitivity decreased greatly with income.

This paper is the first to study the relationship between income dependence and a-insensitivity in the developing countries. A-insensitivity reflects a cognitive component of people's ambiguity attitudes. People who are extremely a-insensitive have the tendency to ignore changes in likelihoods and, hence, they will fail to value the benefit of preventive measures unless these measures completely eliminate the potential losses. They will also fail to value the benefit of a new technology as long as it does not ensure a sure gain. These implications are especially consequential for the poor, who have less margin for making suboptimal decisions. Studies have shown that a-insensitivity can be improved by learning of information 
(Baillon et al. 2017a). Policies promoting adoption of preventive measures such as a vaccine or new technology could therefore aim more at influencing a-insensitive people. For instance, presenting the benefit in a more tangible and less uncertain way can make people less insensitive to the uncertainty induced by the new technology.

The current literature studying ambiguity attitudes in the developing world almost exclusively focuses on ambiguity aversion. The finding of a-insensitivity in this paper adds to this literature by providing confirming evidence of its importance in the developing world. Dimmock et al. (2016b) found that a-insensitivity has predictive power in real life decisions. Studying the predictive power of both components of ambiguity attitude (aversion and a-insensitivity) in real life decisions, including decisions about saving, adoption of new technologies, farmland renting, insurance and migration, can help us better understand income inequalities. It will also provide new insights for policy making.

Acknowledgments I would like to thank the coordinating teachers at the participating schools and the NGO "One-School" organization in China for making this study possible. I received helpful comments from Peter Wakker, Utz Weitzel, Aurélien Baillon, David Schroeder, and Vitalie Spinu. Financial support from the Tinbergen Institution and the Econometrics Institute at Erasmus School of Economics are gratefully acknowledged.

Open Access This article is distributed under the terms of the Creative Commons Attribution 4.0 International License (http://creativecommons.org/licenses/by/4.0/), which permits unrestricted use, distribution, and reproduction in any medium, provided you give appropriate credit to the original author(s) and the source, provide a link to the Creative Commons license, and indicate if changes were made.

\section{Appendix A: Random coefficient model results}

A decision maker's reported matching probability is a function of his subjective probability, and his ambiguity attitudes: $m=f(p, b, a)$. Following Baillon et al. (2017b), we assume a linear dependence of $m$ on $p$ on $(0,1)$ throughout:

$$
m=d+h p \quad \text { for } \quad 0<p<1 \text {. }
$$

Observation A1 Assume the linear dependence as given in Eq. 3. The matching probability is given by:

$$
m=0.5(a-b)+(1-a) p
$$

Proof Consider the linear function as in Eq. 3. I show that $d=0.5(a-b)$ and $h=1-a$.

Note that $3 \overline{m_{s}}=3 d+h$, and similarly $3 \overline{m_{c}}=3 d+2 h$.

By definition, $a=1-\left(3 \overline{m_{c}}-3 \overline{m_{s}}\right)=1-h$. Hence, $h=1-a$. By definition, $b=1-\left(\overline{m_{c}}+\overline{m_{s}}\right)=1-(2 d+h)=a-2 d$. Hence, $d=0.5(a-b)$.

Hence, $m=0.5(a-b)+(1-a) p$. 
Let $m_{k l}(k=1, \ldots, n, l=1, \ldots, m)$ denote subject $k$ 's matching probability for event $l .{ }^{16}$ Matching probability is a function of the subject's subjective probability $p_{k l}$, and ambiguity attitude indices $b_{k}$ and $a_{k}: m_{k l}=f\left(p_{k 1}, p_{k 2}, b_{k}, a_{k}\right){ }^{17}$ Observation A1 gives one specification of the function $f$. To account for the possibility that subjects report their matching probabilities with an error, the reported matching probability is modeled as:

$$
m_{k l}=f\left(p_{k 1}, p_{k 2}, b_{k}, a_{k}\right)+\epsilon_{k l}
$$

where $\epsilon_{k l}$ are independent of each other and follow a normal distribution with mean 0 and standard deviation $\sigma_{\epsilon}$. Error terms $\epsilon_{k l}$ are also assumed to be independent of the random coefficients of subjective probabilities and ambiguity attitude indices specified as follows. Let

$$
\eta_{k}=X_{k}^{\eta} \beta^{\eta}+\xi_{k}^{\eta}, \eta_{k} \in\left\{p_{k 1}, p_{k 2}, b_{k}, a_{k}\right\}
$$

where $\eta_{k}$ is one of the four individual specific parameters, $X_{k}^{\eta}$ are $1 \times K^{\eta}$ vectors specifying $k^{\eta}$ fixed effect regressors, $\beta^{\eta}$ are corresponding vectors of coefficient parameters, and $\xi_{k}^{\eta}$ are unobserved random effects of the parameters at the individual level. For $p_{k 1}, p_{k 2}, b_{k}$ and $a_{k}$, one or more fixed effects are included, depending on different model specifications. ${ }^{18}$ The random effect coefficients $\xi_{k}=\left(\xi_{k}^{p_{1}}, \xi_{k}^{p_{2}}, \xi_{k}^{b}, \xi_{k}^{a}\right)$ follows a jointly normal distribution, independent of each other, and independent of $X^{\eta}$. Let $\xi^{*}$ denote the standardized $\xi: \xi^{*}=\left(\Sigma^{\prime}\right)^{-1} \xi$, where $\Sigma^{\prime} \Sigma$ is the covariance matrix of $\xi$, and $\Sigma=\operatorname{Diag}\left(\sigma_{\xi^{p_{1}}}^{2}, \sigma_{\xi^{p_{2}}}^{2}, \sigma_{\xi^{b}}^{2}, \sigma_{\xi^{a}}^{2}\right)$.

Subject $k$ 's likelihood contribution can be expressed as:

$$
l_{k}=\int_{\mathbb{R}^{4}}\left[\prod_{l=1}^{36} \frac{1}{\sigma_{\epsilon}} \phi\left(\frac{\left(m_{k l}-f\left(p_{k 1}, p_{k 2}, b_{k}, a_{k}\right)\right)}{\sigma_{\epsilon}}\right)\right] \phi\left(\xi^{*}\right) d \xi^{*} .
$$

The econometric specification is similar to that in von Gaudecker et al. (2011) but differs in the following aspects. Their model was for discrete choices in every line of choice lists. Considering that choices within the same choice list are likely correlated, the model in this paper is specified for the stated matching probability. Therefore, the trembling hand error term is not included. The model estimation is done using the nlme package in $\mathrm{R}$.

Three different model specifications accounting for choice errors are considered. Source fixed effects are not included for either ambiguity aversion or a-insensitivity because there are no significant differences in ambiguity attitudes across different sources. ${ }^{19}$ The three models differ in the fixed effect for ambiguity aversion and a-insensitivity. Model M0 includes only the dummy variable urban as fixed effect,

\footnotetext{
${ }^{16}$ The subscript $l$ identifies which single or composite event $(1,2,3,12,13$,or 23$)$ within that source it concerns.

${ }^{17}$ All other probabilities can be expressed in terms of $p_{k 1}$ and $p_{k 2}$.

${ }^{18}$ Source fixed effects are included for both $p_{1}$ and $p_{2}$ as probability sophistication holds only within one source (Chew and Sagi 2008; Abdellaoui et al. 2011).

${ }^{19}$ Including them has little effect on the results and does not affect main conclusions.
} 
Table 5 Random coefficient model: Ambiguity aversion and a-insensitivity

\begin{tabular}{|c|c|c|c|}
\hline & Model M0 & Model M1 & Model M2 \\
\hline \multirow[t]{2}{*}{ a.(Intercept) } & -0.41 & -0.67 & -0.38 \\
\hline & {$[0.03]^{* * *}$} & {$[0.07]^{* * *}$} & {$[0.40]$} \\
\hline \multirow[t]{2}{*}{ a.urban } & 0.12 & 0.43 & 0.78 \\
\hline & {$[0.04]^{* * *}$} & {$[0.10]^{* * *}$} & {$[0.76]$} \\
\hline \multirow[t]{2}{*}{ a.income } & & 1.61 & 1.63 \\
\hline & & {$[0.52] * * *$} & {$[0.51]^{* * *}$} \\
\hline \multirow[t]{2}{*}{ a.grade } & & & -0.00 \\
\hline & & & {$[0.01]$} \\
\hline \multirow[t]{2}{*}{ a.rank } & & & -0.02 \\
\hline & & & {$[0.02]$} \\
\hline \multirow[t]{2}{*}{ a.fav.lan } & & & -0.27 \\
\hline & & & {$[0.10]^{* * *}$} \\
\hline \multirow[t]{2}{*}{ a.urban:income } & & -1.65 & -1.67 \\
\hline & & {$[0.53]^{* * *}$} & {$[0.51]^{* * *}$} \\
\hline \multirow[t]{2}{*}{ a.urban:grade } & & & -0.01 \\
\hline & & & {$[0.01]$} \\
\hline \multirow[t]{2}{*}{ a.urban:rank } & & & 0.00 \\
\hline & & & {$[0.02]$} \\
\hline \multirow[t]{2}{*}{ a.urban:fav.lan } & & & 0.30 \\
\hline & & & {$[0.14]^{* *}$} \\
\hline \multirow[t]{2}{*}{ b.(Intercept) } & -0.04 & -0.11 & -0.31 \\
\hline & {$[0.02]^{* *}$} & {$[0.05]^{* *}$} & {$[0.26]$} \\
\hline \multirow[t]{2}{*}{ b.urban } & 0.06 & 0.10 & 0.54 \\
\hline & {$[0.02] * * *$} & {$[0.07]$} & {$[0.49]$} \\
\hline \multirow[t]{2}{*}{ b.income } & & 0.66 & 0.70 \\
\hline & & {$[0.35]^{*}$} & {$[0.33]^{* *}$} \\
\hline \multirow[t]{2}{*}{ b.grade } & & & 0.00 \\
\hline & & & {$[0.00]$} \\
\hline \multirow[t]{2}{*}{ b.rank } & & & -0.01 \\
\hline & & & {$[0.01]$} \\
\hline \multirow[t]{2}{*}{ b.fav.lan } & & & 0.08 \\
\hline & & & {$[0.06]$} \\
\hline \multirow[t]{2}{*}{ b.urban:income } & & -0.64 & -0.68 \\
\hline & & {$[0.35]^{*}$} & {$[0.33]^{* *}$} \\
\hline \multirow[t]{2}{*}{ b.urban:grade } & & & -0.01 \\
\hline & & & {$[0.01]$} \\
\hline \multirow[t]{2}{*}{ b.urban:rank } & & & 0.01 \\
\hline & & & {$[0.01]$} \\
\hline \multirow[t]{2}{*}{ b.urban:fav.lan } & & & -0.08 \\
\hline & & & {$[0.09]$} \\
\hline
\end{tabular}


Table 5 (continued)

\begin{tabular}{llll}
\hline & Model M0 & Model M1 & Model M2 \\
\hline$\sigma_{\xi^{a}}$ & 0.09 & 0.33 & 0.32 \\
$\sigma_{\xi^{b}}$ & 0.11 & 0.26 & 0.24 \\
$\sigma_{\epsilon}$ & 0.25 & 0.22 & 0.22 \\
Log.Lik & -396.75 & 36.71 & 42.02 \\
No.Obs & 5443 & 4225 & 4190 \\
\hline
\end{tabular}

Entries starting with sp.(a.) followed by a variable name reports the fixed effect estimates of the variable for ambiguity aversion (a-insensitivity). Fixed and random effect results on $p_{1}$ and $p_{2}$ are in Table 6 . Number of observations in Model M1 and M2 are smaller than in M0 due to missing values of self-reported demographic variables. It is about 6 times of the number of observations in Model 1 and Model 2 in Table 3 for the following two reasons. In Model 1, every index is calculated based on 6 matching probabilities, so 6 matching probabilities give 1 observation. Whereas in Model M1 and M2, every matching probablity is taken as one observation. Moreover, in Model 1 and 2, indices were calculated only if all 6 matching probabilities were non-missing. However, in Model M1 and M2, this restriction no longer applies

Table 6 Random coefficient model: $p_{1}$ and $p_{2}$

Entries starting with p1.(p2.)

followed by a variable name reports the fixed effect estimates of each source (identified by the language) for $p_{1}$ and $p_{2}$

\begin{tabular}{llll}
\hline & Model M0 & Model M1 & Model M2 \\
\hline p1.BJ & 0.31 & 0.25 & 0.26 \\
& {$[0.02]^{* * *}$} & {$[0.02]^{* * *}$} & {$[0.02]^{* * *}$} \\
p1.SH & 0.29 & 0.38 & 0.38 \\
& {$[0.02]^{* * *}$} & {$[0.02]^{* * *}$} & {$[0.02]^{* * *}$} \\
p1.EN & 0.30 & 0.26 & 0.26 \\
& {$[0.02]^{* * *}$} & {$[0.02]^{* * *}$} & {$[0.02]^{* * *}$} \\
p1.JP & 0.32 & 0.31 & 0.31 \\
& {$[0.02]^{* * *}$} & {$[0.02]^{* * *}$} & {$[0.02]^{* * *}$} \\
p1.KR & 0.31 & 0.24 & 0.23 \\
& {$[0.02]^{* * *}$} & {$[0.02]^{* * *}$} & {$[0.02]^{* * *}$} \\
p1.NL & 0.33 & 0.37 & 0.37 \\
& {$[0.02]^{* * *}$} & {$[0.02]^{* * *}$} & {$[0.02]^{* * *}$} \\
p2.BJ & 0.43 & 0.43 & 0.43 \\
& {$[0.02]^{* * *}$} & {$[0.02]^{* * *}$} & {$[0.02]^{* * *}$} \\
p2.SH & 0.40 & 0.37 & 0.37 \\
& {$[0.02]^{* * *}$} & {$[0.02]^{* * *}$} & {$[0.02]^{* * *}$} \\
p2.EN & 0.39 & 0.43 & 0.42 \\
& {$[0.02]^{* * *}$} & {$[0.02]^{* * *}$} & {$[0.02]^{* * * *}$} \\
p2.JP & 0.36 & 0.37 & 0.37 \\
& {$[0.02]^{* * *}$} & {$[0.02]^{* * *}$} & {$[0.02]^{* * *}$} \\
p2.KR & 0.38 & 0.50 & 0.50 \\
& {$[0.02]^{* * *}$} & {$[0.02]^{* * *}$} & {$[0.02]^{* * *}$} \\
p2.NL & 0.39 & 0.36 & 0.37 \\
& {$[0.02]^{* * *}$} & {$[0.02]^{* * *}$} & {$[0.02]^{* * *}$} \\
$\sigma_{\xi} p_{1}$ & 0.12 & 0.07 & 0.07 \\
$\sigma_{\xi} p_{2}$ & 0.14 & 0.08 & 0.09 \\
\hline & & & \\
& & &
\end{tabular}


which also accounts for potential correlations of observations from the same subject. Model M1 included urban, income, and their interactions. Model M2 included variables that were significant in Table 3. Tables 5 and 6 report the estimation results of the random coefficient model. The main effects are similar to the regression models.

\section{Appendix B: Including choices with multiple switching points}

This section reports test results with choices exhibiting multiple switching points included. To infer the matching probability from these choices, I recorded the first and the last time that choices switch from the ambiguous Lottery B to the risky Lottery A, and considered the subjects to be indifferent between the two lotteries in the region in between, where they switched multiple times. The middle point of the two switching points was taken as their matching probability.

Table 7 Ambiguity attitudes: Urban and rural separate

\begin{tabular}{|c|c|c|c|c|c|c|c|c|}
\hline & \multicolumn{4}{|c|}{ Ambiguity aversion } & \multicolumn{4}{|c|}{ A-insensitivity } \\
\hline & \multicolumn{2}{|l|}{ Rural } & \multicolumn{2}{|l|}{ Urban } & \multicolumn{2}{|l|}{ Rural } & \multicolumn{2}{|l|}{ Urban } \\
\hline & (1) & (2) & (3) & (4) & (5) & (6) & (7) & (8) \\
\hline income & $\begin{array}{l}-0.405 \\
(0.254)\end{array}$ & $\begin{array}{l}-0.391^{*} \\
(0.221)\end{array}$ & $\begin{array}{l}-0.020 \\
(0.018)\end{array}$ & $\begin{array}{l}-0.024 \\
(0.017)\end{array}$ & $\begin{array}{l}-1.429^{* * *} \\
(0.332)\end{array}$ & $\begin{array}{l}-1.409^{* * *} \\
(0.282)\end{array}$ & $\begin{array}{l}0.036^{* * *} \\
(0.014)\end{array}$ & $\begin{array}{l}0.069^{* * *} \\
(0.019)\end{array}$ \\
\hline male & & $\begin{array}{l}0.068 \\
(0.063)\end{array}$ & & $\begin{array}{l}0.010 \\
(0.067)\end{array}$ & & $\begin{array}{l}0.018 \\
(0.090)\end{array}$ & & $\begin{array}{l}0.001 \\
(0.113)\end{array}$ \\
\hline age & & $\begin{array}{l}-0.005 \\
(0.037)\end{array}$ & & $\begin{array}{l}-0.076^{*} \\
(0.043)\end{array}$ & & $\begin{array}{l}0.036 \\
(0.041)\end{array}$ & & $\begin{array}{l}0.130 \\
(0.081)\end{array}$ \\
\hline no.sib & & $\begin{array}{l}-0.025 \\
(0.021)\end{array}$ & & $\begin{array}{l}-0.029 \\
(0.039)\end{array}$ & & $\begin{array}{l}0.028 \\
(0.038)\end{array}$ & & $\begin{array}{l}-0.051 \\
(0.098)\end{array}$ \\
\hline crt & & $\begin{array}{l}-0.116 \\
(0.100)\end{array}$ & & $\begin{array}{l}-0.208 \\
(0.138)\end{array}$ & & $\begin{array}{l}-0.020 \\
(0.118)\end{array}$ & & $\begin{array}{l}0.255 \\
(0.223)\end{array}$ \\
\hline grade & & $\begin{array}{l}0.001 \\
(0.002)\end{array}$ & & $\begin{array}{l}0.0002 \\
(0.005)\end{array}$ & & $\begin{array}{l}0.001 \\
(0.003)\end{array}$ & & $\begin{array}{l}0.022^{* *} \\
(0.009)\end{array}$ \\
\hline fav.lan & & $\begin{array}{l}0.007 \\
(0.065)\end{array}$ & & $\begin{array}{l}-0.005 \\
(0.071)\end{array}$ & & $\begin{array}{l}0.203^{* * *} \\
(0.079)\end{array}$ & & $\begin{array}{l}-0.043 \\
(0.123)\end{array}$ \\
\hline rank & & $\begin{array}{l}0.004 \\
(0.005)\end{array}$ & & $\begin{array}{l}0.002 \\
(0.005)\end{array}$ & & $\begin{array}{l}0.019^{*} \\
(0.011)\end{array}$ & & $\begin{array}{l}0.011 \\
(0.010)\end{array}$ \\
\hline Constant & $\begin{array}{l}0.046 \\
(0.038)\end{array}$ & $\begin{array}{l}0.156 \\
(0.727)\end{array}$ & $\begin{array}{l}0.003 \\
(0.042)\end{array}$ & $\begin{array}{l}1.374 \\
(0.877)\end{array}$ & $\begin{array}{l}0.771^{* * *} \\
(0.051)\end{array}$ & $\begin{array}{l}-0.152 \\
(0.847)\end{array}$ & $\begin{array}{l}0.360^{* * *} \\
(0.068)\end{array}$ & $\begin{array}{l}-3.484^{* *} \\
(1.677)\end{array}$ \\
\hline Observations & 461 & 443 & 377 & 371 & 461 & 443 & 377 & 371 \\
\hline $\mathrm{R}^{2}$ & 0.016 & 0.032 & 0.008 & 0.049 & 0.058 & 0.095 & 0.007 & 0.056 \\
\hline
\end{tabular}

${ }^{*} \mathrm{p}<0.1 ;{ }^{* *} \mathrm{p}<0.05 ;{ }^{* * *} \mathrm{p}<0.01$ 
Table 8 Urban and rural pooled with interaction terms

Dependent variable:

Ambiguity aversion

A-insensitivity

(1)

(2)

(3)

(4)

\begin{tabular}{|c|c|c|c|c|}
\hline \multirow[t]{2}{*}{ urban } & -0.042 & 1.217 & $-0.411^{* * *}$ & $-3.332^{*}$ \\
\hline & $(0.057)$ & (1.139) & $(0.085)$ & $(1.879)$ \\
\hline \multirow[t]{2}{*}{ income } & -0.405 & $-0.391^{*}$ & $-1.429^{* * *}$ & $-1.409^{* * *}$ \\
\hline & $(0.254)$ & $(0.221)$ & $(0.332)$ & $(0.282)$ \\
\hline \multirow[t]{2}{*}{ male } & & 0.068 & & 0.018 \\
\hline & & $(0.063)$ & & $(0.090)$ \\
\hline \multirow[t]{2}{*}{ age } & & -0.005 & & 0.036 \\
\hline & & $(0.037)$ & & $(0.041)$ \\
\hline \multirow[t]{2}{*}{ no.sib } & & -0.025 & & 0.028 \\
\hline & & $(0.021)$ & & $(0.038)$ \\
\hline \multirow[t]{2}{*}{ crt } & & -0.116 & & -0.020 \\
\hline & & $(0.100)$ & & $(0.118)$ \\
\hline \multirow[t]{2}{*}{ grade } & & 0.001 & & 0.001 \\
\hline & & $(0.002)$ & & $(0.003)$ \\
\hline \multirow[t]{2}{*}{ fav.lan } & & 0.007 & & $0.203^{* * *}$ \\
\hline & & $(0.065)$ & & $(0.079)$ \\
\hline \multirow[t]{2}{*}{ rank } & & 0.004 & & $0.019^{*}$ \\
\hline & & $(0.005)$ & & $(0.011)$ \\
\hline \multirow[t]{2}{*}{ urban:income } & 0.385 & $0.367^{*}$ & $1.465^{* * *}$ & $1.478^{* * *}$ \\
\hline & $(0.255)$ & $(0.221)$ & $(0.332)$ & $(0.283)$ \\
\hline \multirow[t]{2}{*}{ urban:male } & & -0.058 & & -0.017 \\
\hline & & $(0.092)$ & & $(0.145)$ \\
\hline \multirow[t]{2}{*}{ urban:age } & & -0.071 & & 0.094 \\
\hline & & $(0.057)$ & & $(0.091)$ \\
\hline \multirow[t]{2}{*}{ urban:no.sib } & & -0.005 & & -0.079 \\
\hline & & $(0.044)$ & & $(0.105)$ \\
\hline \multirow[t]{2}{*}{ urban:crt } & & -0.092 & & 0.275 \\
\hline & & $(0.170)$ & & $(0.252)$ \\
\hline \multirow[t]{2}{*}{ urban:grade } & & -0.0004 & & $0.021^{* *}$ \\
\hline & & $(0.006)$ & & $(0.010)$ \\
\hline \multirow[t]{2}{*}{ urban:fav.lan } & & -0.012 & & $-0.246^{*}$ \\
\hline & & $(0.096)$ & & $(0.146)$ \\
\hline \multirow[t]{2}{*}{ urban:rank } & & -0.002 & & -0.008 \\
\hline & & $(0.007)$ & & $(0.015)$ \\
\hline \multirow[t]{2}{*}{ Constant } & 0.046 & 0.156 & $0.771^{* * *}$ & -0.152 \\
\hline & $(0.038)$ & $(0.727)$ & $(0.051)$ & $(0.847)$ \\
\hline Observations & 838 & 814 & 838 & 814 \\
\hline $\mathrm{R}^{2}$ & 0.014 & 0.045 & 0.073 & 0.113 \\
\hline
\end{tabular}

${ }^{*} \mathrm{p}<0.1 ;{ }^{* *} \mathrm{p}<0.05 ;{ }^{* * *} \mathrm{p}<0.01$ 
Table 7 presents the regression results for rural and urban separately on the data including multiple switching points. Similarly, Table 8 presents the regression results of the pooled regression with interaction terms on this data. Results are similar.

\section{References}

Abdellaoui, M., Baillon, A., Placido, L., \& Wakker, P.P. (2011). The rich domain of uncertainty: Source functions and their experimental implementation. American Economic Review, 101(2), 695-723.

Akay, A., Martinsson, P., Medhin, H., \& Trautmann, S.T. (2012). Attitudes toward uncertainty among the poor: An experiment in rural Ethiopia. Theory and Decision, 73(3), 453-464.

Alpizar, F., Carlsson, F., \& Naranjo, M.A. (2011). The effect of ambiguous risk, and coordination on farmers' adaptation to climate change - A framed field experiment. Ecological Economics, 70(12), 2317-2326.

Baillon, A., Cabantous, L., \& Wakker, P.P. (2012). Aggregating imprecise or conflicting beliefs: An experimental investigation using modern ambiguity theories. Journal of Risk and Uncertainty, 44(2), $115-147$.

Baillon, A., Bleichrodt, H., Keskin, U., l'Haridon, O., \& Li, C. (2017a). The effect of learning on ambiguity attitudes. Management Science. https://doi.org/10.1287/mnsc.2016.2700 forthcoming.

Baillon, A., Huang, Z., Selim, A., \& Wakker, P. (2017b). Measuring ambiguity attitudes for all (natural) events. Working paper.

Becker, G.M., DeGroot, M.H., \& Marschak, J. (1963). Stochastic models of choice behavior. Behavioral Science, 8(1), 41-55.

Bianchi, M., \& Tallon, J.M. (2014). Ambiguity preferences and portfolio choices. Evidence from the field. Mimeo.

Binmore, K., Stewart, L., \& Voorhoeve, A. (2012). How much ambiguity aversion? Journal of Risk and Uncertainty, 45(3), 215-238.

Borghans, L., Heckman, J.J., Golsteyn, B.H., \& Meijers, H. (2009). Gender differences in risk aversion and ambiguity aversion. Journal of the European Economic Association, 7(2-3), 649-658.

Brunnermeier, M.K., \& Nagel, S. (2008). Do wealth fluctuations generate time-varying risk aversion? Micro-evidence on individuals' asset allocation. American Economic Review, 98(3), 713-736.

Butler, J.V., Guiso, L., \& Jappelli, T. (2014). The role of intuition and reasoning in driving aversion to risk and ambiguity. Theory and Decision, 77(4), 455-484.

Cardenas, J.C., \& Carpenter, J. (2013). Risk attitudes and economic well-being in Latin America. Journal of Development Economics, 103, 52-61.

Chesson, H.W., \& Viscusi, W.K. (2003). Commonalities in time and ambiguity aversion for long-term risks. Theory and Decision, 54(1), 57-71.

Chew, S.H., \& Sagi, J.S. (2008). Small worlds: Modeling attitudes toward sources of uncertainty. Journal of Economic Theory, 139(1), 1-24.

Chew, S.H., Ebstein, R.P., \& Zhong, S. (2012). Ambiguity aversion and familiarity bias: Evidence from behavioral and gene association studies. Journal of Risk and Uncertainty, 44(1), 1-18.

Cohen, A., \& Einav, L. (2007). Estimating risk preferences from deductible choice. American Economic Review, 97(3), 745-788.

Dimmock, S.G., Kouwenberg, R., Mitchell, O.S., \& Peijnenburg, K. (2015). Estimating ambiguity preferences and perceptions in multiple prior models: Evidence from the field. Journal of Risk and Uncertainty, 51(3), 219-244.

Dimmock, S.G., Kouwenberg, R., Mitchell, O.S., \& Peijnenburg, K. (2016a). Ambiguity aversion and household portfolio choice puzzles: Empirical evidence. Journal of Financial Economics, 119(3), 559-577.

Dimmock, S.G., Kouwenberg, R., \& Wakker, P.P. (2016b). Ambiguity attitudes in a large representative sample. Management Science, 62(5), 1363-1380.

Dow, J., \& da Costa Werlang, S.R. (1992). Uncertainty aversion, risk aversion, and the optimal choice of portfolio. Econometrica, 60(1), 197-204.

Ellsberg, D. (1961). Risk, ambiguity, and the Savage axioms. The Quarterly Journal of Economics, 75(4), 643-669. 
Ellsberg, D. (2011). Notes on the origin of the Ellsberg urns (introduction to the symposium issue). Economic Theory, 48, 221-227.

Engle-Warnick, J.C., Escobal, J., \& Laszlo, S.C. (2011). Ambiguity aversion and portfolio choice in smallscale Peruvian farming. The BE Journal of Economic Analysis \& Policy, 11(1).

Frederick, S. (2005). Cognitive reflection and decision making. Journal of Economic Perspectives, $25-42$.

von Gaudecker, H.M., van Soest, A., \& Wengström, E. (2011). Heterogeneity in risky choice behavior in a broad population. American Economic Review, 101(2), 664-694.

Gilboa, I., \& Schmeidler, D. (1989). Maxmin expected utility with non-unique prior. Journal of Mathematical Economics, 18(2), 141-153.

Gonzalez, R., \& Wu, G. (1999). On the shape of the probability weighting function. Cognitive Psychology, $38,129-166$.

Grant, S., Kline, J.J., \& Quiggin, J. (2014). A matter of interpretation: Ambiguous contracts and liquidated damages. Games and Economic Behavior, 85, 180-187.

Grant, S., Kline, J.J., \& Quiggin, J. (2016). Recursive CARA preferences and contracting under ambiguity. Working paper.

Halevy, Y. (2007). Ellsberg revisited: An experimental study. Econometrica, 75(2), 503-536.

Heath, C., \& Tversky, A. (1991). Preference and belief: Ambiguity and competence in choice under uncertainty. Journal of Risk and Uncertainty, 4(1), 5-28.

Hey, J., \& Orme, C. (1994). Investigating generalizations of expected utility theory using experimental data. Econometrica, 1291-1326.

Hogarth, R.M., \& Einhorn, H.J. (1990). Venture theory: A model of decision weights. Management Science, 36(7), 780-803.

Kachelmeier, S.J., \& Shehata, M. (1992). Examining risk preferences under high monetary incentives: Experimental evidence from the People's Republic of China. American Economic Review, 82(5), $1120-1141$.

Kahn, B.E., \& Sarin, R.K. (1988). Modeling ambiguity in decisions under uncertainty. Journal of Consumer Research, 265-272.

Kilka, M., \& Weber, M. (2001). What determines the shape of the probability weighting function under uncertainty? Management Science, 47, 1712-1726.

Kocher, M.G., Lahno, A.M., \& Trautmann, S.T. (2015). Ambiguity aversion is the exception. Working paper.

Kothiyal, A., Spinu, V., \& Wakker, P.P. (2014). An experimental test of prospect theory for predicting choice under ambiguity. Journal of Risk and Uncertainty, 48(1), 1-17.

Machina, M.J., \& Schmeidler, D. (1992). A more robust definition of subjective probability. Econometrica: Journal of the Econometric Society, 745-780.

Mani, A., Mullainathan, S., Shafir, E., \& Zhao, J. (2013). Poverty impedes cognitive function. Science, 341, 976-980.

Meyer, D.J., \& Meyer, J. (2005). Relative risk aversion: What do we know? Journal of Risk and Uncertainty, 31(3), 243-262.

Ogaki, M., \& Zhang, Q. (2001). Decreasing relative risk aversion and tests of risk sharing. Econometrica, 69(2), 515-526.

Ross, N., Santos, P., \& Capon, T. (2012). Risk, ambiguity and the adoption of new technologies: Experimental evidence from a developing economy. Working paper.

Rottenstreich, Y., \& Hsee, C.K. (2001). Money, kisses, and electric shocks: On the affective psychology of risk. Psychological Science, 12(3), 185-190.

Schmeidler, D. (1989). Subjective probability and expected utility without additivity. Econometrica, 57, 571-587.

Shattuck, M., \& Wagner, C. (2016). Peter Fishburn's analysis of ambiguity. Theory and Decision, 81(2), 153-165. https://doi.org/10.1007/s11238-016-9534-3.

Spears, D. (2013). Poverty and probability: Aspiration and aversion to compound lotteries in El Salvador and India. Experimental Economics, 16(3), 263-284.

Sutter, M., Kocher, M.G., Glätzle-Rützler, D., \& Trautmann, S.T. (2013). Impatience and uncertainty: Experimental decisions predict adolescents' field behavior. American Economic Review, 103(1), 510531.

Trautmann, S.T., \& van de Kuilen, G. (2015). Ambiguity attitudes. In Keren, G., \& Wu, G. (Eds.) The Wiley Blackwell Handbook of Judgment and Decision Making (pp. 89-116). Oxford, UK: Blackwell.

Tversky, A., \& Fox, C.R. (1995). Weighing risk and uncertainty. Psychological Review, 102(2), 269. 
Tversky, A., \& Wakker, P. (1995). Risk attitudes and decision weights. Econometrica, 63(6), 1255-1280.

Viscusi, W.K. (1989). Prospective reference theory: Toward an explanation of the paradoxes. Journal of Risk and Uncertainty, 2(3), 235-263.

Viscusi, W.K. (1995). Government action, biases in risk perception, and insurance decisions. The Geneva Papers on Risk and Insurance Theory, 20(1), 93-110.

Viscusi, W.K., \& Chesson, H. (1999). Hopes and fears: The conflicting effects of risk ambiguity. Theory and Decision, 47(2), 157-184.

Viscusi, W.K., \& Evans, W.N. (2006). Behavioral probabilities. Journal of Risk and Uncertainty, 32(1), 5-15.

Wakker, P.P. (2010). Prospect theory: For risk and ambiguity Vol. 44. Cambridge: Cambridge University Press.

Weeks, J. (1970). Uncertainty, risk, and wealth and income distribution in peasant agriculture. The Journal of Development Studies, 7(1), 28-36.

Yesuf, M., \& Bluffstone, R.A. (2009). Poverty, risk aversion, and path dependence in low-income countries: Experimental evidence from Ethiopia. American Journal of Agricultural Economics, 91(4), 1022-1037.

Zeckhauser, J.R., \& Viscusi, W. (1990). Risk within reason. Science, 248, 559-563. 